\title{
Interaction between the MJO and High-Frequency Waves over the Maritime Continent in Boreal Winter
}

\author{
YAN ZHU AND TIM LI \\ Key Laboratory of Meteorological Disaster, Ministry of Education/Joint International Research Laboratory of Climate and \\ Environmental Change/Collaborative Innovation Center on Forecast and Evaluation of Meteorological Disasters, Nanjing \\ University of Information Science and Technology, Nanjing, China, and Department of Atmospheric Sciences, \\ and School of Ocean and Earth Science and Technology, University of Hawai'i at Mānoa, Honolulu, Hawaii
}

MiNG ZHAO

NOAA/Geophysical Fluid Dynamics Laboratory, Princeton, New Jersey

TOMOE NASUNO

Department of Seamless Environmental Prediction Research, JAMSTEC, Yokohama, Japan

(Manuscript received 8 August 2018, in final form 21 March 2019)

\begin{abstract}
The two-way interaction between Madden-Julian oscillation (MJO) and higher-frequency waves (HFW) over the Maritime Continent (MC) during boreal winter of 1984-2005 is investigated. It is noted from observational analysis that strengthened (weakened) HFW activity appears to the west (east) of and under MJO convection during the MJO active phase and the opposite is seen during the MJO suppressed phase. Sensitivity model experiments indicate that the control of HFW activity by MJO is through change of the background vertical wind shear and specific humidity. The upscale feedbacks from HFW to MJO through nonlinear rectification of condensational heating and eddy momentum transport are also investigated with observational data. A significantly large amount $(25 \%-40 \%)$ of positive heating anomaly $\left(\widetilde{Q_{2}}\right)$ at low levels to the east of MJO convection is contributed by nonlinear rectification of HFW. This nonlinear rectification is primarily attributed to eddy meridional moisture advection. A momentum budget diagnosis reveals that $60 \%$ of MJO zonal wind tendency at $850 \mathrm{hPa}$ is attributed to the nonlinear interaction of HFW with other scale flows. Among them, the largest contribution arises from eddy zonal momentum flux divergence $\left[-\left(\overline{\partial u^{\prime} u^{\prime} / \partial x}\right)\right]$. Easterly (westerly) vertical shear to the west (east) of MJO convection during the MJO active phase causes the strengthening (weakening) of the HFW zonal wind anomaly. This leads to the increase (decrease) of eddy momentum flux activity to the east (west) of the MJO convection, which causes a positive (negative) eddy zonal momentum flux divergence in the zonal wind transitional region during the MJO active (suppressed) phase, favoring the eastward propagation of the MJO.
\end{abstract}

\section{Introduction}

The Madden-Julian oscillation (MJO) (all acronyms have been listed in Table 1) is the dominant intraseasonal oscillation in tropics, with typical periodicity between 20 and 100 days (Madden and Julian 1972; Knutson and Weickmann 1987; Hendon and Salby 1994). The convective envelope associated with MJO moves slowly eastward at a phase speed of about $5-10 \mathrm{~m} \mathrm{~s}^{-1}$ (Neelin et al. 1987; Wang 1988; Maloney 2009; Hsu and Li 2012). The structure of the MJO is characterized by a zonally planetary

Corresponding author: Tim Li, timli@hawaii.edu length scale with global wavenumber 1-2 (Wang and Rui 1990; Li and Zhou 2009), a Kelvin wave and Rossby wave couplet pattern (Rui and Wang 1990; Wang and Li 1994; Li and Wang 1994; Adames and Wallace 2014), and a vertically tilted structure in vertical velocity and moisture fields (Sperber 2003; Hsu and Li 2012).

Most MJO events initiate in the west Indian Ocean (Matthews 2008; Zhao et al. 2013; Straub 2013), weaken over the Maritime Continent (MC), and continue their eastward journey after passing the MC. Kim et al. (2014) emphasized the role of suppressed convective anomalies to the east of MJO convective center in promoting MJO passing the MC. Feng et al. (2015) investigated the cause 
TABLE 1. List of acronyms.

\begin{tabular}{ll}
\hline \hline Acronyms & \multicolumn{1}{c}{ Explanation } \\
\hline AE & Advection of EKE by eddy \\
AM & Advections of EKE by LFBS and MJO scale flow \\
CA & $\begin{array}{c}\text { Baroclinic energy conversed from eddy available } \\
\text { potential energy } \\
\text { Barotropic energy conversion from LFBS and } \\
\text { CK }\end{array}$ \\
& MJO scale flow \\
EKE & Eddy kinetic energy \\
EZMFD & Eddy zonal momentum flux divergence \\
FG & Generation of EKE through convergence of eddy \\
& geopotential fluxes \\
HFW & High-frequency waves \\
ISO & Intraseasonal oscillation \\
MC & Maritime Continent \\
MJO & Madden-Julian oscillation \\
MRG & Mixed Rossby-gravity wave \\
OLR & Outgoing longwave radiation \\
PBL & Planetary boundary layer \\
TD & Tropical depression \\
\hline
\end{tabular}

of propagating and nonpropagating $\mathrm{MJO}$ events across the $\mathrm{MC}$, and concluded the nonpropagating $\mathrm{MJO}$ events are attributed to dry Rossby wave invasion that dissipates the MJO convection development.

MJO multimodel intercomparison projects were aiming at improving mechanism understanding and simulation capability of MJO (Lin et al. 2006; Jiang et al. 2015). Eight distinguishing climate models' data were diagnosed to test their capability of MJO simulation. Results from the diagnosis of eight distinguishing climate models showed that only half of the models could capture realistic MJO intensity change in $\mathrm{MC}$ (Kim et al. 2009). Previous works indicated that the MC is a critical location for MJO eastward propagation and the models had a deficiency in capturing MJO variation and phase speed there. Therefore, a further understanding of MJO evolution in the MC region is of great importance.

Various previous studies have been devoted to understanding the interaction between the intraseasonal oscillation (ISO) and higher-frequency waves (HFW) (e.g., Chang et al. 2005; Dickinson and Molinari 2002; Kerns and Chen 2014; Zhu and Hendon 2015; Kang and Tziperman 2018). Chang et al. (2005) demonstrated that the MJO exerted a great influence on the frequency and life span of synoptic disturbances in the MC. Straub and Kiladis (2003) pointed out more active mixed Rossbygravity wave (MRG) and tropical depression (TD) activity in MJO active phases. One mechanism of the ISO affecting HFW is through barotropic energy conversion. For instance, by separating a variable into the lowfrequency background state, ISO, and higher-frequency components, Hsu et al. (2011) demonstrated that during the ISO active phase there is barotropic energy conversion from ISO flow to higher-frequency eddies. A more challenging aspect of MJO-HFW interaction is HFW feedback to MJO. It has been shown that HFW may exert an upscale feedback to summer ISO through nonlinear modulation of MJO-scale latent heat flux and diabatic heating (Zhou and Li 2010; Hsu and Li 2011). Another upscale feedback process is through eddy momentum transport (e.g., Hsu and Li 2011; Liu and Wang 2013). Most previous studies concentrated either on the large-scale control of ISO on HFW or on upscale feedback of HFW to ISO. In this study, we would like to discuss two-way interaction between the MJO and HFW, with a special focus on the MC region.

The objective of the present study is to reveal the observational characteristics of the MJO-HFW relationship and physical mechanisms behind their two-way interaction in the MC region. We will take both observational and modeling approaches. Section 2 describes the datasets, methods, and model. Section 3 consists of two parts. The first part is the observational investigation of characteristics of HFW modulation by MJO and physical mechanisms that lead to such modulation. The second part is to reveal the relative importance of MJO dynamic and thermodynamic fields in modulating HFW intensity. In section 4 , the nonlinear rectification of intraseasonal apparent moisture sink field $\left(\widetilde{Q_{2}}\right)$ by HFW and the dynamic upscale feedback due to eddy momentum transport are examined respectively. Finally, a summary is given in section 5 .

\section{Data, methodology, and model description}

\section{a. Data}

Primary observational datasets used in the present analysis include 1) interpolated outgoing longwave radiation (OLR) from National Oceanic and Atmospheric Administration (NOAA) polar-orbiting satellites (Liebmann and Smith 1996) and 2) atmospheric three-dimensional fields including zonal and meridional wind $(u$ and $v)$, temperature $(T)$, pressure vertical velocity $(\omega)$, geopotential height $(\phi)$, and specific humidity $(q)$ from the European Centre for Medium-Range Weather Forecasts (ECMWF) interim reanalysis (ERA-Interim) (Dee et al. 2011). All data above are daily data with horizontal resolution of $2.5^{\circ}$ latitude $\times$ $2.5^{\circ}$ longitude for 1984-2005. In this study, we focus on the boreal winter season (November-April).

\section{b. Methodology}

For the data analysis, we first removed the climatological annual cycle. Then a Lanczos bandpass filter (Duchon 1979) was used to derive the HFW component ( $A^{\prime} ;<20$ days), MJO component ( $\tilde{A} ; 20-100$ days), and low-frequency background state (LFBS; $\bar{A}>100$ days) 
component. The Maritime Continent is a major focus region, where there is remarkable intraseasonal (20100 days) variability in the anomalous OLR field (figure not shown). An MJO index is defined according to the box $\left(15^{\circ}-5^{\circ} \mathrm{S}, 125^{\circ}-135^{\circ} \mathrm{E}\right)$ averaged anomalous OLR time series. An active (suppressed) MJO phase is defined when the OLR time series is smaller (larger) than one negative (positive) standard deviation. There are a total of 611 days and 55 counts of MJO active phase, and 580 days and 58 counts of MJO suppressed phase. The horizontal structure of $\mathrm{HFW}$ was constructed by regression onto 20-day high-pass filtered vorticity time series averaged over the same $\mathrm{MC}$ box region. The $\mathrm{MJO}$ structures are then constructed based on the composition of MJO active and suppressed phases.

\section{c. Model description}

An intermediate tropical atmospheric model (Wang and Li 1993; Wang and Li 1994; Wang and Xie 1997) is used to understand the relative role of $\mathrm{MJO}$ dynamic and thermodynamic fields on the development of HFW. The model consists of a two-level free atmosphere and a barotropic boundary layer. The model covers the global tropical domain $\left(40^{\circ} \mathrm{S}-40^{\circ} \mathrm{N}\right)$. It is an anomalous model with specified basic states derived from interpolated ERA-Interim reanalysis data in winter. The basic state consists of both the climatological mean state and active or suppressed MJO field. The upper-level and lowerlevel background wind fields are from $250-$ and $850-\mathrm{hPa}$ reanalysis data, while the background temperature field at the middle level is calculated from basic-state geopotential height field. The vertical profile of background specific humidity follows an empirical formula (Wang and Li 1993), and the background surface specific humidity is derived from ERA-Interim data. This model has been used for various tropical wave dynamics studies, such as the study of role of background moisture and vertical shear in modulating boreal summer intraseasonal oscillation (Deng and Li 2016), and the study of effect of seasonally varying basic state to convectively coupled Rossby waves (Wang and Chen 2017). Although the simple model is able to simulate the climate mean state in the tropical Pacific and the general structure and evolution of the MJO (Wang and Li 1993, 1994), it has some deficiencies. For example, the model has only two vertical levels in the free atmosphere and thus it cannot describe the multicloud structure of the MJO. The convective heating scheme is rather crude, and it depends on column integrated moisture convergence and surface evaporation. An advantage of the model is that it can be used to study the evolution of tropical disturbances under a specified background mean state. This fits well the objective of the current study, which is to investigate the relative role of background vertical shear and moisture fields associated with the MJO on the HFW activity.

\section{Modulation of HFW by the MJO}

\section{a. Observational characteristics}

The active phase of the MJO in the MC is characterized by a large-scale convective anomaly with a pronounced negative outgoing longwave radiation (OLR) anomaly centered over the MC region (Fig. 1a). Low-level westerly anomalies appear under and to the west of the MJO convection while easterly anomalies appear to the east. A mirror image of the wind and OLR anomaly pattern appears during the MJO suppressed phase (Fig. 1b). To examine the extent to which the MJO modulates the intensity of HFW, the differences of standard deviation of 20-day high-pass filtered vorticity at $850 \mathrm{hPa}$ between the MJO active (suppressed) phase and climatology are shown in Fig. 2. During the MJO active (suppressed) phase, HFW vorticity standard deviation is greater (smaller) than climatology over most of the MC. HFW activity east of $150^{\circ}$ displays a distinctive feature. The intensity of HFW in that region is weakened during the MJO active phase. Given the region-dependent HFW characteristics, we first investigate $\mathrm{HFW}$ activity regressed over $15^{\circ}-5^{\circ} \mathrm{S}, 125^{\circ}-$ $135^{\circ} \mathrm{E}$ (the region is shown as a blue box in Figs. 1 and 2). Figure 3 shows $850-\mathrm{hPa}$ wind and vorticity fields regressed onto box-averaged 20-day high-pass filtered 850-hPa vorticity time series during the MJO active and suppressed phases. The cyclone and anticyclone of HFW appear alternatively at the eastern end and propagate westward in climatological condition (Figs. 3a-e), which is analogous to the synoptic wave train defined by Lau and Lau (1990). The waves are northeast-southwest oriented with wavelength about $2500 \mathrm{~km}$. The northeastsouthwest orientation of HFW is clearly presented during the MJO active phase and normal climate state, but much less during the MJO suppressed phase. The activities of HFW are similar as shown in vorticity standard deviation, with stronger vorticity anomalies and more violent wind anomalies during the active phase (Figs. $3 \mathrm{f}-\mathrm{j}$ ) and weaker vorticity anomalies and more peaceful wind anomalies during the suppressed phase (Figs. 3k-o).

The ISO scale modulation of HFW may be understood through barotropic energy conversion, $\widetilde{\mathrm{CK}}$. From Hsu et al. (2011), every independent variable is also separated into three components $\left(A=\bar{A}+\tilde{A}+A^{\prime}\right)$ and the tendency of intraseasonal eddy kinetic energy [ $\widehat{\mathrm{EKE}}, \widehat{\mathrm{EKE}}=$ $\left.\overline{\left(u^{\prime 2}+v^{\prime 2}\right) / 2}\right]$ is attributed to several processes:

$$
\frac{\partial \widetilde{\mathrm{EKE}}}{\partial t}=\widetilde{\mathrm{CK}}+\widetilde{\mathrm{CA}}+\widetilde{\mathrm{AM}}+\widetilde{\mathrm{AE}}+\widetilde{\mathrm{FG}},
$$




\section{a. OLR \& $850 \mathrm{hPa}$ wind (MJO active phase)}

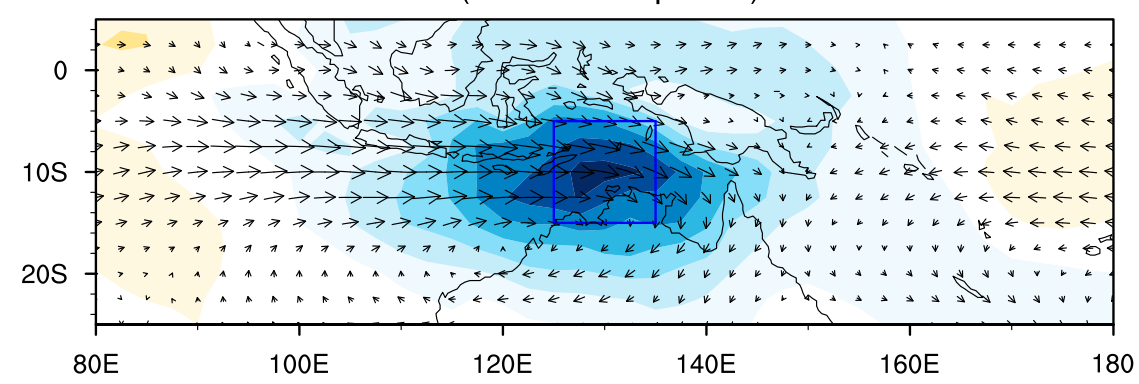

b. OLR \& 850hPa wind (MJO suppressed phase)

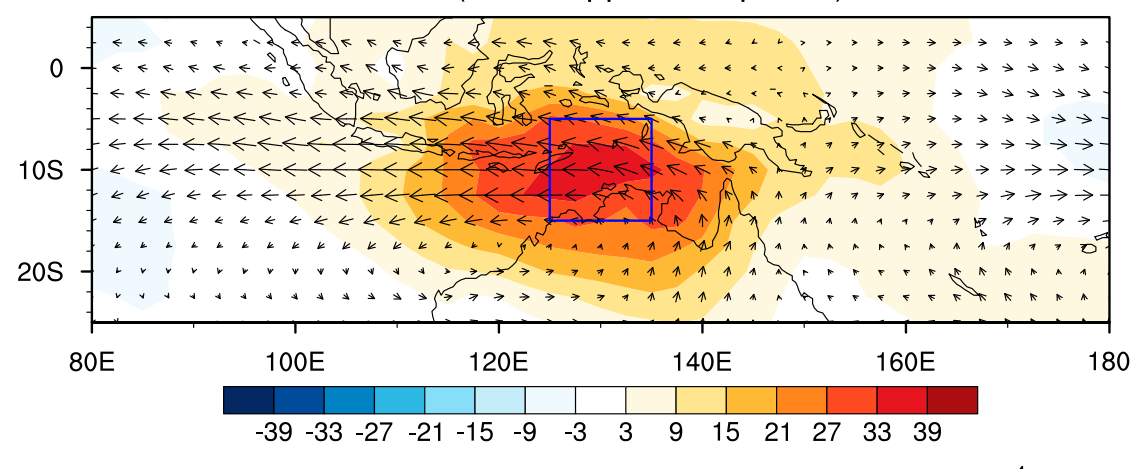

FIG. 1. (a) OLR anomalies (shading; unit: $\mathrm{W} \mathrm{m}^{-2}$ ) and $850-\mathrm{hPa}$ wind anomalies (vector; unit: $\mathrm{m} \mathrm{s}^{-1}$ ) for the MJO active phase composite. (b) As in (a), but for the MJO suppressed phase composite. The blue box indicates the region $15^{\circ}-5^{\circ} \mathrm{S}, 125^{\circ}-135^{\circ} \mathrm{E}$.

where $\mathrm{CK}$ donates barotropic energy conversion from LFBS and MJO scale flow, CA represents baroclinic energy conversed from eddy available potential energy, AM is advections of EKE by LFBS and MJO scale flow,
$\mathrm{AE}$ indicates advection of EKE by eddy, and FG is the generation of EKE through convergence of eddy geopotential fluxes [a more detailed description of Eq. (1) is given in Hsu et al. (2011)]. Only the $\widetilde{\mathrm{CK}}$ and $\widehat{\mathrm{AM}}$ involve

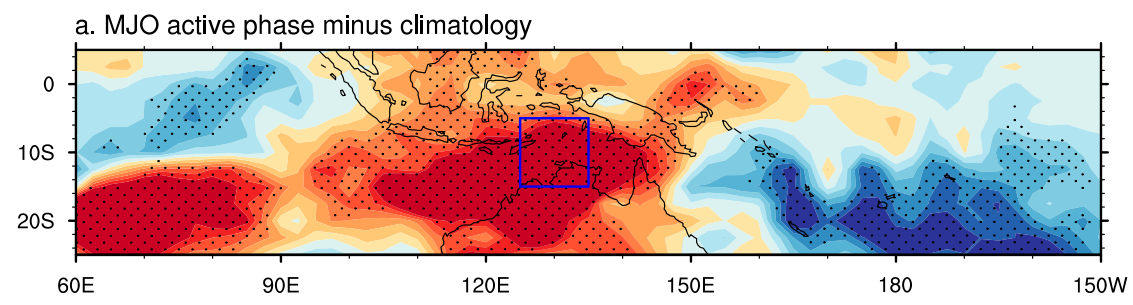

b. MJO suppressed phase minus climatology

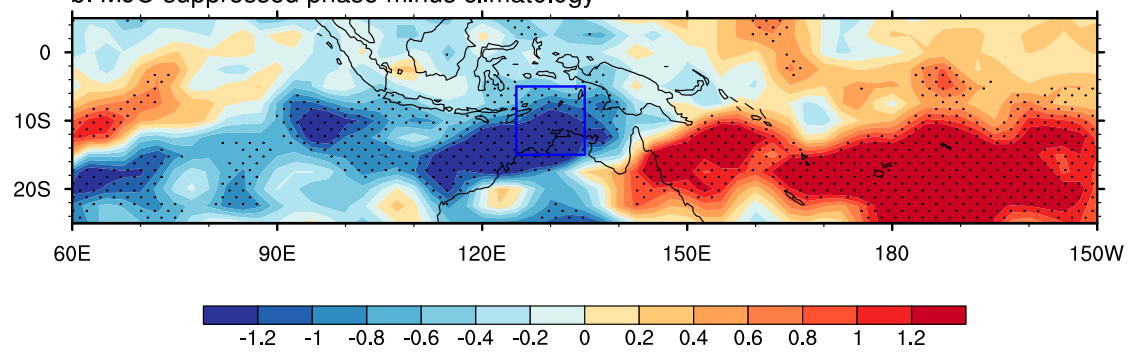

FIG. 2. (a) The difference of 20-day high-passed vorticity standard deviation in $850 \mathrm{hPa}$ (unit: $10^{-6} \mathrm{~s}^{-1}$ ) between the MJO active phase and climatological condition. (b) As in (a), but for the MJO suppressed phase and climatological condition. Stippled region is significant at $95 \%$ level. The blue box indicates region of $15^{\circ}-5^{\circ} \mathrm{S}, 125^{\circ}-135^{\circ} \mathrm{E}$. 

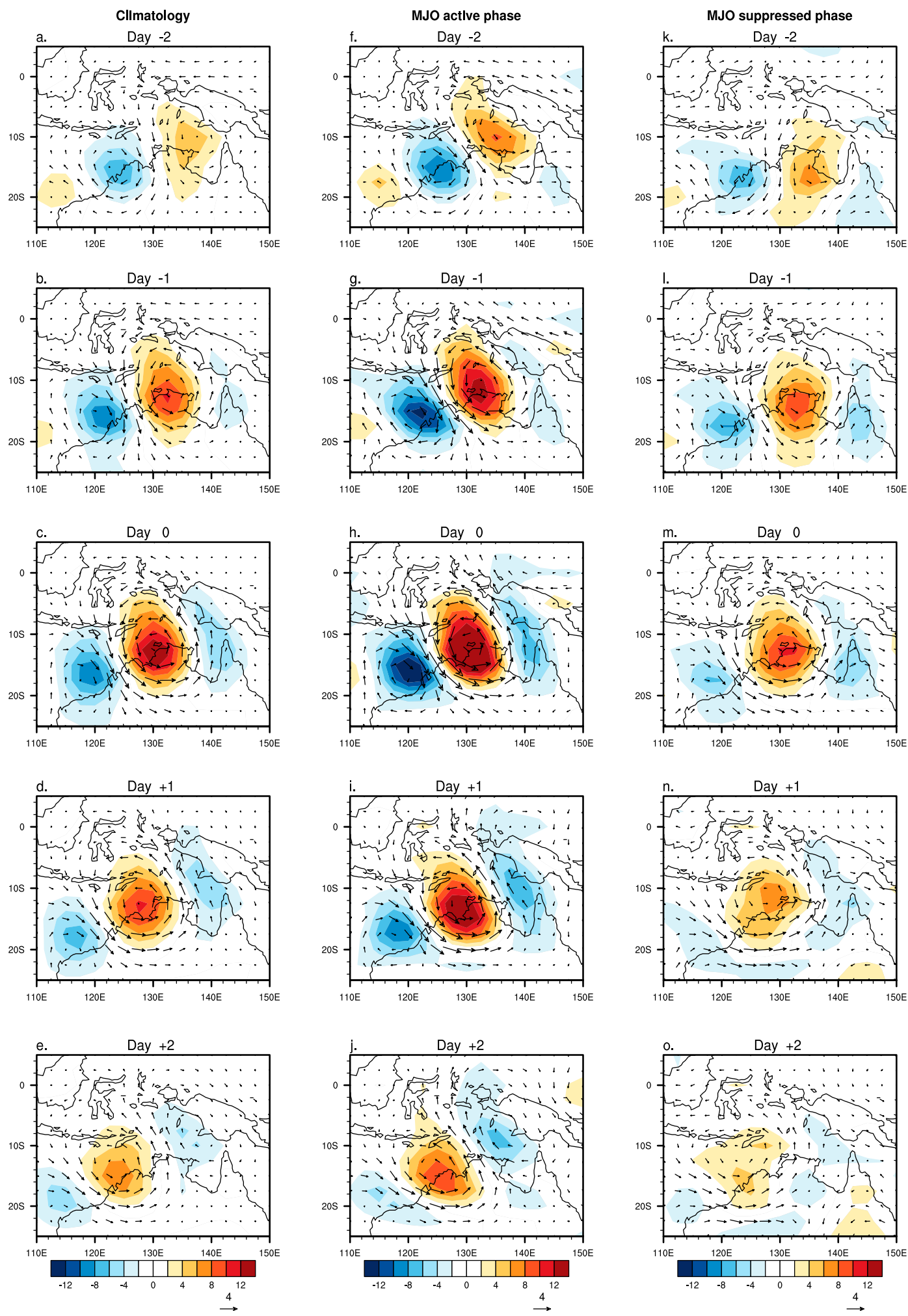

FIG. 3. (a)-(e) Time evolution of 20-day high-passed wind (vector; unit: $\mathrm{m} \mathrm{s}^{-1}$ ) and vorticity (shading; unit: $10^{-6} \mathrm{~s}^{-1}$ ) at $850 \mathrm{hPa}$ for climatological condition. (f)-(j),(k)-(o) As in (a)-(e), but vector and shading are 20-day highpassed wind and vorticity during the MJO active phase and suppressed phase, respectively. 

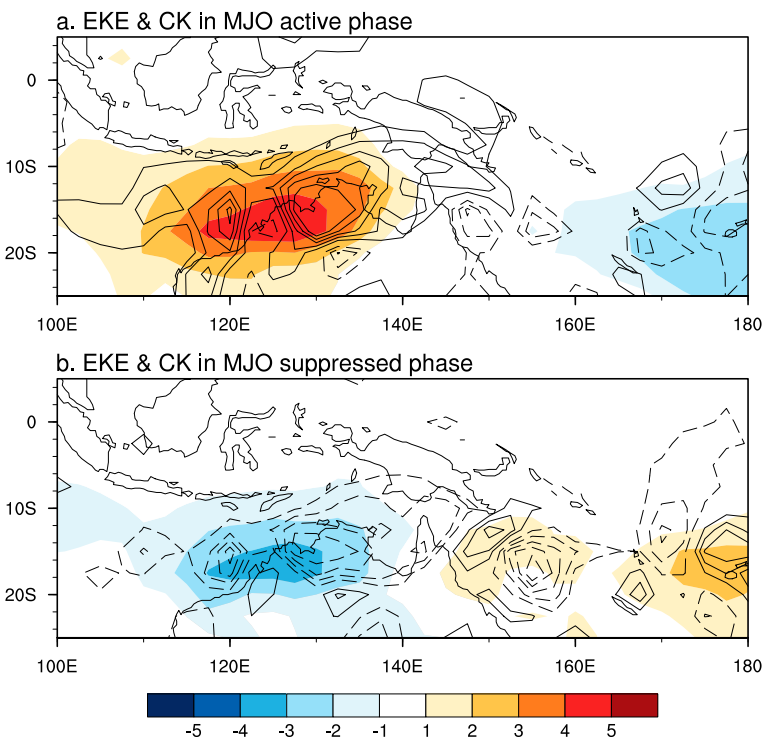

FIG. 4. (a) $\widetilde{\mathrm{EKE}}$ anomaly (shading; unit: $\mathrm{m}^{2} \cdot \mathrm{s}^{-2}$ ) and $\widetilde{\mathrm{CK}}$ anomaly at $850 \mathrm{hPa}$ (contour; unit: $10^{-5} \mathrm{~m}^{2} \mathrm{~s}^{-3}$ ) for the MJO active phase composite; zero line is not shown. (b) As in (a), but for the MJO suppressed phase composite.

HFW and other time scale interaction and CK is the dominant contribution in these two terms. The $\widetilde{\mathrm{EKE}}$ anomaly is positive during the MJO active phase composite and negative during the MJO suppressed phase composite. The positive $\widehat{\mathrm{EKE}}$ anomaly is predominantly attributed to the positive intraseasonal barotropic energy conversion $(\widetilde{\mathrm{CK}})$ during the MJO active phase (Fig. 4a). This indicates that kinetic energy is transferred from MJO to HFW. However, negative $\overline{\mathrm{CK}}$ during the MJO suppressed phase (Fig. 4b) indicates that the MJO extracts energy from HFW. A further diagnosis shows that two largest contributors in $\widetilde{\mathrm{CK}}$ are $\overline{-u^{\prime} u^{\prime}(\partial \tilde{u} / \partial x)}$ and $-u^{\prime} v^{\prime}(\partial \tilde{u} / \partial y)$, both related to MJO zonal wind anomalies. For northeast-southwest-oriented HFW in the Southern Hemisphere, $u^{\prime} u^{\prime}>0$ and $u^{\prime} v^{\prime}<0$ (Fig. 3). Thus, for a convergent and cyclonic MJO flow, $(\partial \tilde{u} / \partial x)<0$ and $(\partial \tilde{u} / \partial y)>0$ (Fig. 1). Thus, both $\overline{-u^{\prime} u^{\prime}(\partial \tilde{u} / \partial x)}$ and $-u^{\prime} v^{\prime}(\partial \tilde{u} / \partial y)$ positively (negatively) contribute to $\widetilde{\mathrm{CK}}$ during the MJO active (suppressed) phase.

The region-dependent HFW activity shown in Fig. 2 is likely attributed to MJO-scale background flow condition. It is noted that there are an easterly wind shear anomaly and a pronounced positive specific humidity anomaly to the west of $150^{\circ}$ while a westerly vertical shear and less moisture appear to the east of $150^{\circ}$ (Figs. 5a,b). According to theoretical studies by Wang and Xie (1996) and Li (2006), an easterly shear background state favors stronger development of HFW wind anomalies in lower troposphere. The enhanced cyclonic perturbation in the lower troposphere results in a
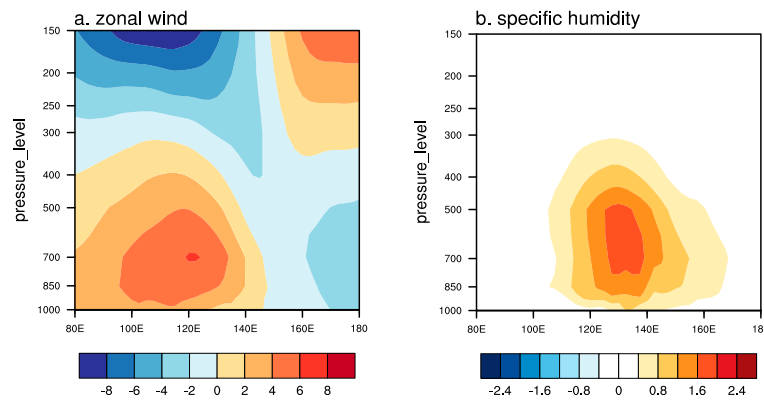

FIG. 5. (a) Pressure-longitude cross section of intraseasonal filtered zonal wind anomaly (unit: $\mathrm{m} \mathrm{s}^{-1}$ ) averaged over $15^{\circ}-5^{\circ} \mathrm{S}$ for the MJO active phase minus suppressed phase composite. (b) As in (a), but for the specific humidity anomaly (unit: $\mathrm{g} \mathrm{kg}^{-1}$ ).

stronger convergence in the planetary boundary layer (PBL) (Ge et al. 2007), which favors more latent heat release and strengthens HFW activity. In addition to vertical shear, the increase of background moisture also favors the growth of HFW activity. The relative roles of background vertical shear and moisture will be examined in idealized numerical experiments in the following subsection. To the east of $150^{\circ} \mathrm{E}$, westerly shear is pronounced, which would weaken HFW activity.

\section{b. Relative role of MJO dynamic and thermodynamic fields in modulating HFW activity - simple model experiments}

In this section, sensitivity experiments with an intermediate tropical atmospheric model were implemented to investigate the relative role of MJO vertical wind shear anomalies, and specific humidity anomalies in modulating HFW intensity variation. Initially, a Rossby wave perturbation is placed at $180^{\circ}$ (Fig. 6a). This Rossby wave has a zonal wind $(u)$, meridional wind $(v)$, and potential height $(\phi)$ structure following Matsuno (1966), with a zonal wavelength of $3000 \mathrm{~km}$. This initial perturbation resembles the synoptic wave train pattern discussed by Lau and Lau (1990). In the control experiment (CTL), the Rossby wave perturbation is placed in the northern winter background mean state. In the subsequent sensitivity experiments, the MJO wind and specific humidity anomaly fields (Fig. 6) were superposed on the CTL background mean state. In EXP1, the domain $\left(20^{\circ} \mathrm{S}-0^{\circ}, 90^{\circ}-140^{\circ} \mathrm{E}\right)$ averaged vertical wind shear field was specified during the MJO active or suppressed phase. In EXP2, the domain-averaged specific humidity anomalies at 700 and $900 \mathrm{hPa}$ were specified during the MJO active or suppressed phase. In EXP3, both wind and specific humidity anomalies were specified.

The model is integrated for 30 days. Following Deng and Li (2016), the eddy kinetic energy $\left[\mathrm{EKE}=\left(u^{\prime 2}+v^{\prime 2}\right) / 2\right]$ 
a. Rossby wave
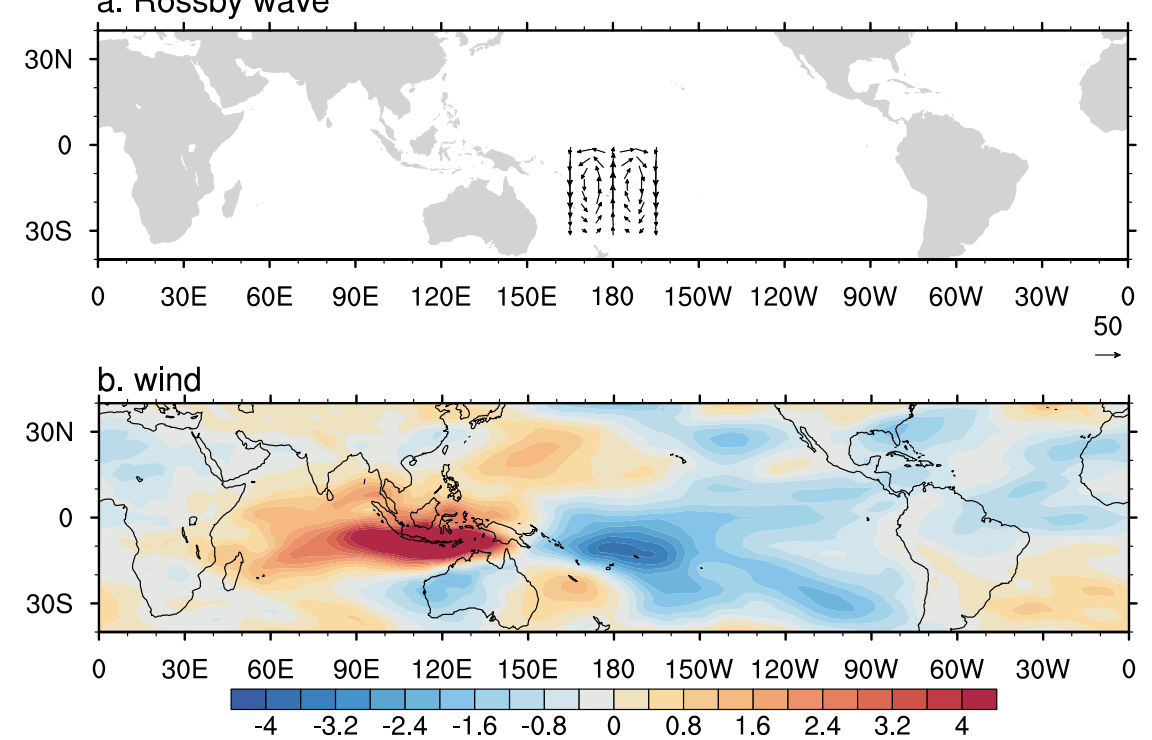

c. specific humidity

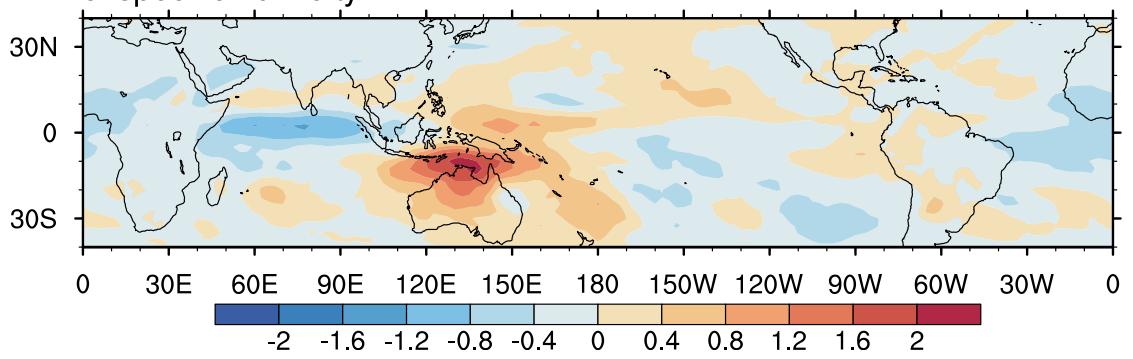

FIG. 6. (a) The location of initial Rossby wave perturbation. (b) Intraseasonal filtered zonal wind anomaly at $850 \mathrm{hPa}$ of MJO active phase minus suppressed phase composite (unit: $\mathrm{m} \mathrm{s}^{-1}$ ). (c) As in (b), but for the specific humidity anomaly (unit: $\mathrm{g} \mathrm{kg}^{-1}$ ).

and precipitation rate were used as indices to measure the intensity of the perturbation. Because the wind and precipitation of Rossby waves are mainly confined to $20^{\circ} \mathrm{S}-0^{\circ}, 60^{\circ} \mathrm{E}-160^{\circ} \mathrm{W}$ from day 5 to day 25 , two indices are averaged in this region. Consistent with observational analysis, both the eddy kinetic energy and precipitation rate are larger (smaller) in experiments with positive (negative) wind shear anomaly or (and) positive (negative) specific humidity anomaly than the CTL experiment (Fig. 7). For all 21 days, $10 \%-15 \%$ of Rossby waves intensity variation can be explained by vertical wind shear anomalies and $85 \%-90 \%$ is related to specific humidity anomalies. Thus, numerical model experiments suggested that strengthened HFW activity under and to the west of the MJO convective center is caused by increased moisture as well as anomalous easterly shear. The weakened HFW activity to the east of MJO convective center is likely attributable to the westerly vertical shear and weakened specific humidity.

\section{Feedback of HFW to MJO}

In this section, we analyze the contribution of nonlinearly rectified HFW to MJO based on observational data. First, we focus on the nonlinear rectification of HFW on intraseasonal diabatic heating anomalies, in particular, the congestus heating in front of MJO deep convection. Second, we concentrate on the role of higher-frequency eddy momentum transport on MJOscale momentum tendency.

\section{a. Nonlinear rectification of intraseasonal condensational heating anomalies by $\mathrm{HFW}$}

The intraseasonal anomaly of apparent moisture sink $\left(\widetilde{Q_{2}}\right)$ is determined by moisture tendency, horizontal moisture advection, and vertical moisture advection, according to Yanai et al. (1973):

$$
\widetilde{Q_{2}}=-L \frac{\widetilde{\partial q}}{\partial t}-L(\overline{\mathbf{V} \cdot \nabla q})-L\left(\widetilde{\omega \frac{\partial q}{\partial p}}\right)
$$



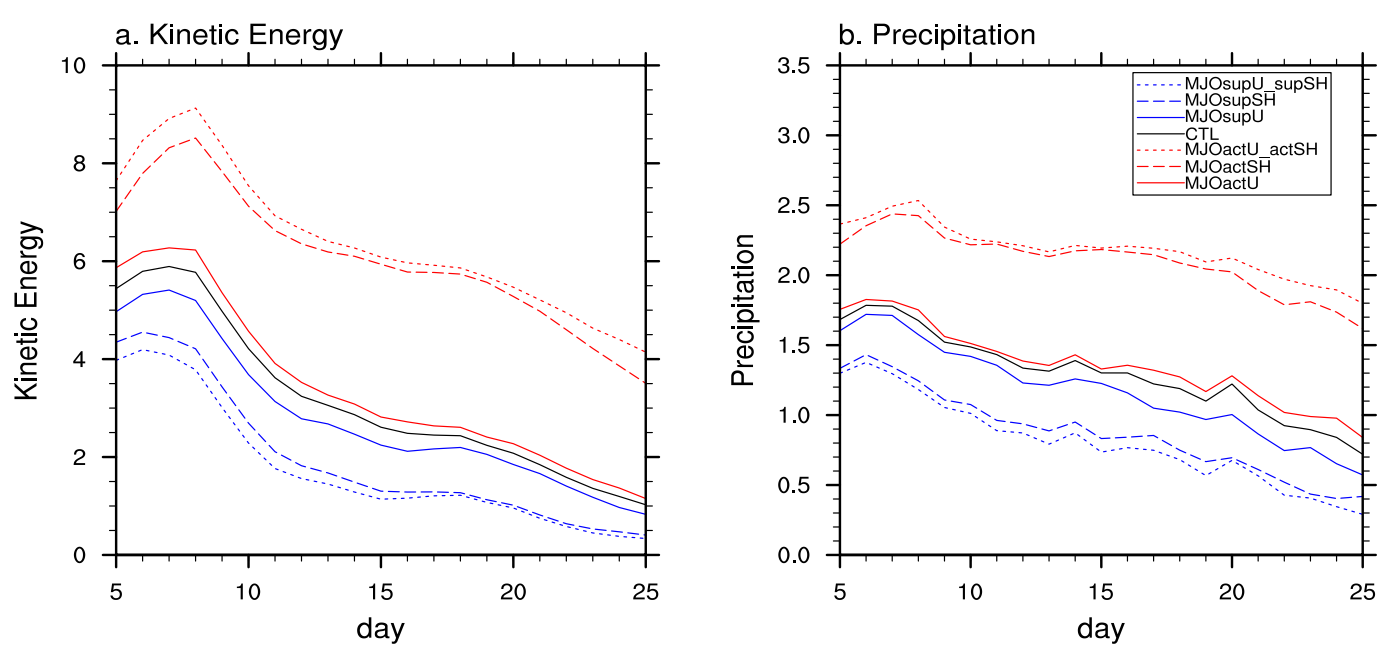

FIG. 7. Time evolution of (a) kinetic energy (unit: $\mathrm{m}^{2} \mathrm{~s}^{-2}$ ) and (b) precipitation rate $\left(\mathrm{mm} \mathrm{day}^{-1}\right.$ ) from day 5 to day 25 of experiments. Black line is for CTL, red lines are experiments with anomaly of MJO active phase, and blue lines are experiments with anomaly of MJO suppressed phase. Solid red and blue lines are experiments with vertical wind shear anomaly. Dashed red and blue lines are experiments with specific humidity anomaly. Red dots and blue lines are experiments with both vertical wind shear anomaly and specific humidity anomaly.

where $L$ is the latent heat of condensation, $q$ is the specific humidity, $t$ denotes time, $\mathbf{V}$ is the horizontal velocity vector, $\nabla$ is the horizontal gradient operator, $\omega$ is the vertical pressure velocity, $p$ is the pressure, and $Q_{2}$ represents the latent heating due to condensation, evaporation, and subgrid-scale moisture flux convergence.

There are two diagnostics to calculate the nonlinearly rectified $Q_{2}$ field according to $\mathrm{Hsu}$ and $\mathrm{Li}$ (2011). The first one is based on the nonlinear interaction between the LFBS component and HFW component without explicitly involving the ISO component. Denoting the intraseasonal component as $\tilde{A}$, the high-frequency component as $A^{\prime}$, and the LFBS component as $\bar{A}$, nonlinearly rectified $\widetilde{Q_{2} \text { LH }}$ may be expressed as

$$
\begin{aligned}
\widetilde{Q_{2 \_} \mathrm{LH}}= & -L\left(u^{\prime}+\bar{u}\right) \frac{\partial\left(q^{\prime}+\bar{q}\right)}{\partial x}-L\left(v^{\prime}+\bar{v}\right) \frac{\partial\left(q^{\prime}+\bar{q}\right)}{\partial y} \\
& -L\left(\omega^{\prime}+\bar{\omega}\right) \frac{\partial\left(q^{\prime}+\bar{q}\right)}{\partial p}
\end{aligned}
$$

The second diagnostic is based on the subtraction of that calculated LFBS and ISO component from the total $Q_{2}$ field (i.e., the T-LI diagnostic; Hsu and Li 2011). Here the total $\widetilde{Q}_{2}$ field is calculated based on Eq. (1) with $A=\bar{A}+\tilde{A}+A^{\prime}$. The nonlinearly rectified $\overline{Q_{2} \text { T-LI }}$ may be expressed as

$$
\overline{Q_{2 \_ \text {T-LI }}}=\widetilde{Q_{2}}-\left[\overline{-L(\tilde{u}+\bar{u}) \frac{\partial(\tilde{q}+\bar{q})}{\partial x}}-\overline{L(\tilde{v}+\bar{v}) \frac{\partial(\tilde{q}+\bar{q})}{\partial y}}-\overline{\left.L(\tilde{\omega}+\bar{\omega}) \frac{\partial(\tilde{q}+\bar{q})}{\partial p}\right]} .\right.
$$

Different from $\overline{Q_{2} \text { LH }}, \overline{Q_{2} \text { T-LI }}$ includes the nonlinear interaction between HFW and the ISO component. The terms in the Eqs. (2)-(4) are divided by specific heat at constant pressure $\left(C_{p}\right)$.

The left panel of Fig. 8 shows the evolution of zonalvertical $\widetilde{Q_{2}}$ profile from day -6 to day 2 . Here day 0 denotes the time when maximum MJO convection is located at $10^{\circ} \mathrm{S}, 130^{\circ} \mathrm{E}$. It is seen that from the pressure-longitude cross section (Figs. 8a-e) that condensational heating of shallow clouds, implied by a positive $\widetilde{Q_{2}}$ anomaly below $700 \mathrm{hPa}$, appears to the east of MJO deep convection. Note that $Q_{2}$ appears tilting westward with height, with a maximum in the upper troposphere over the MJO convective center. The eastward propagation and gradual enhancement of $\widetilde{Q_{2}}$ can be clearly seen from Fig. 8 . The nonlinearly rectified intraseasonal $Q_{2}$ terms $\left(\widehat{Q_{2 \_} \mathrm{LH}}\right.$ and $\overline{Q_{2} \text { T-LI }}$ ) primarily show a positive (negative) tendency in the upper (lower) troposphere in the active period of MJO convection over the MC. This represents enhanced vertical transport of moisture and latent heat release by HFW, although these are secondary to other terms (e.g., the advection of LFBS specific humidity by intraseasonal winds) in magnitude. In the preconditioning phase (e.g., day -6 in the MC or days -6 to 0 in 

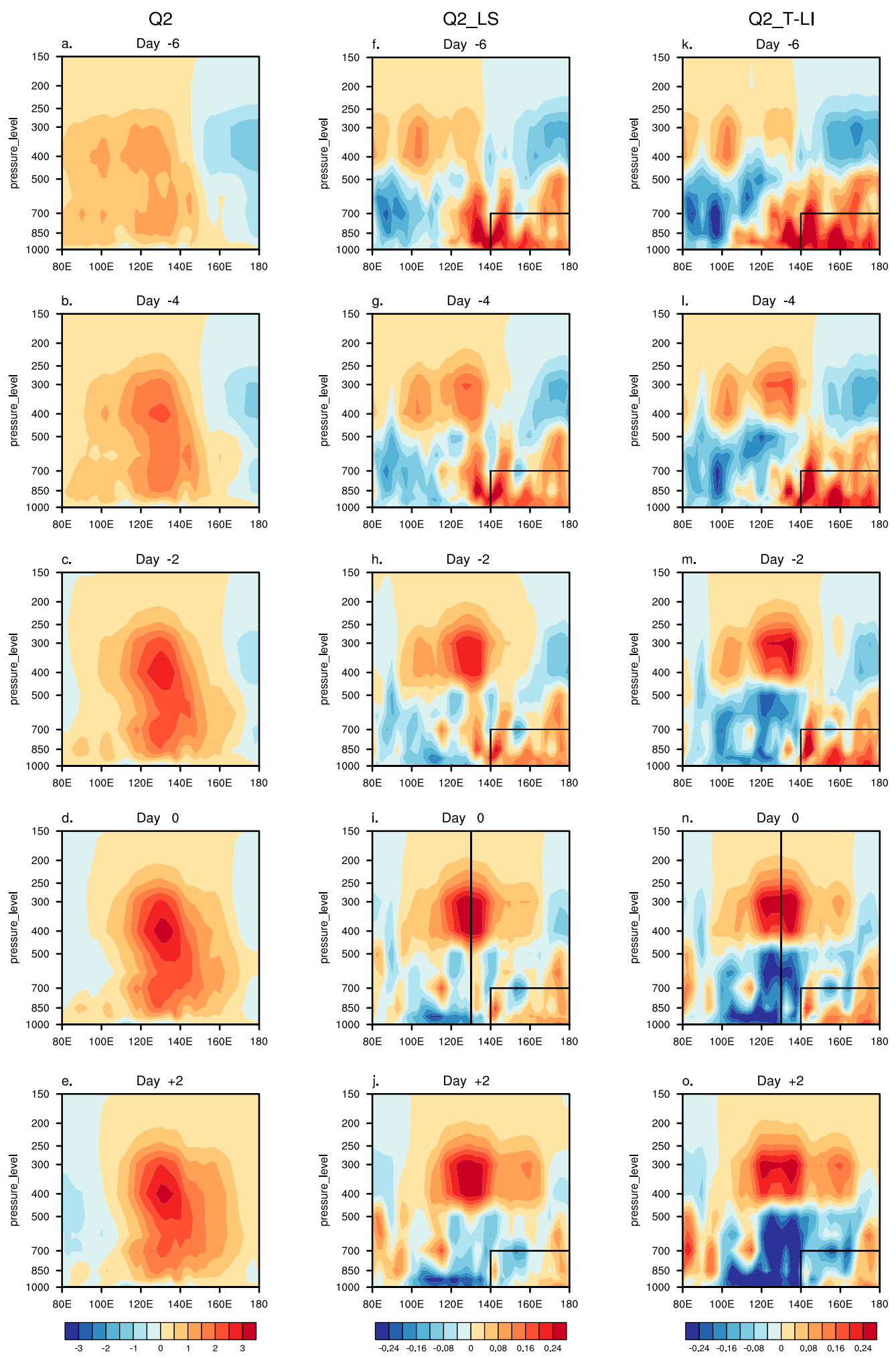

FIG. 8. (a)-(e) Time evolution of pressure-longitude cross section of intraseasonal filtered $Q_{2} / c_{p}$ anomalies (unit: $\mathrm{K}$ day $^{-1}$ ) averaged over $15^{\circ}-5^{\circ} \mathrm{S}$ for $\mathrm{MJO}$ active phase minus suppressed phase composite. (f)-(j),(k)-(o) As in (a)-(e), but for intraseasonal filtered $Q_{2 \_ \text {LH }} / c_{\mathrm{p}}$ and $Q_{2 \_\mathrm{T}-\mathrm{LI}} / c_{\mathrm{p}}$ anomalies, respectively (unit: $\mathrm{K}$ day ${ }^{-1}$ ). [Boxes are dominant HFW upscale feedback contributed longitude $\left(140 \mathrm{E}^{\circ}-180^{\circ}\right)$ in PBL $(1000-700 \mathrm{hPa})$; thick line in day 0 is center of OLR.] 


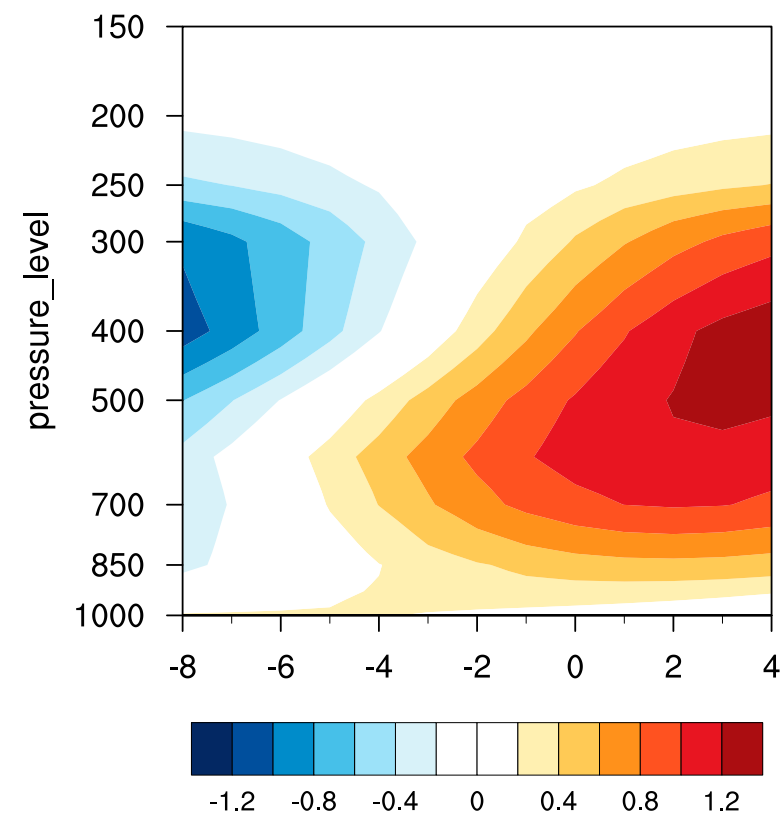

FIG. 9. Pressure-time cross section of $\widetilde{Q_{2}}$ (unit: $\mathrm{K} \mathrm{day}^{-1}$ ) evolution averaged over $15^{\circ}-5^{\circ} \mathrm{S}, 140 \mathrm{E}^{\circ}-180^{\circ}$ from day -8 to day 4 for MJO active phase minus suppressed phase composite.

$\left.140^{\circ} \mathrm{E}-180^{\circ}\right)$, positive anomalies of $\overline{Q_{2} \mathrm{LH}}$ and $\overline{Q_{2} \text { T-LI }}$ are formed in the lower to midtroposphere. These HFW effects on the MJO are consistent with those found in the previous studies (e.g., Nasuno et al. 2015, 2017).

From a fixed location (say, averaged at $140^{\circ} \mathrm{E}-180^{\circ}$ ), the gradual deepening of $Q_{2}$ from day -8 to day +4 is clearly observed in Fig. 9. This evolution feature is consistent with the schematic diagram shown by Benedict and Randall (2007) and results by Zhu et al. (2009), who illustrated the precursory signals of shallow and congestus clouds and gradual deepening of atmospheric moist layer prior to the arrival of deep convection. Thus, an important question that needs to be addressed is to what extent the low-level positive $\widetilde{Q_{2}}$ to the east of MJO convection (Figs. 8a-e) is contributed by nonlinear rectification processes that involve highfrequency eddies (Figs. 8f-o).

Averaging over the dominant HFW nonlinearly rectified region $\left(15^{\circ}-5^{\circ} \mathrm{S}, 140^{\circ} \mathrm{E}-180^{\circ}\right)$ in $\mathrm{PBL}$, one may calculate the relative contribution of $\widetilde{Q_{2 \_} \text {LH }}$ and $\overline{Q_{2 \_ \text {T-LI }}}$ to the total $\widetilde{Q_{2}}$ field (Fig. 10). The ratio is about $25 \%-$ $40 \%$ when a vertical integration of $1000-700 \mathrm{hPa}$ is used, and it increases to $40 \%-60 \%$ when a vertical integration of $1000-850 \mathrm{hPa}$ is applied. Such a ratio reflects how strong the nonlinear rectification of HFW is in feeding back to MJO, particularly in affecting the establishment of shallow and congestus clouds in front of MJO deep convection.

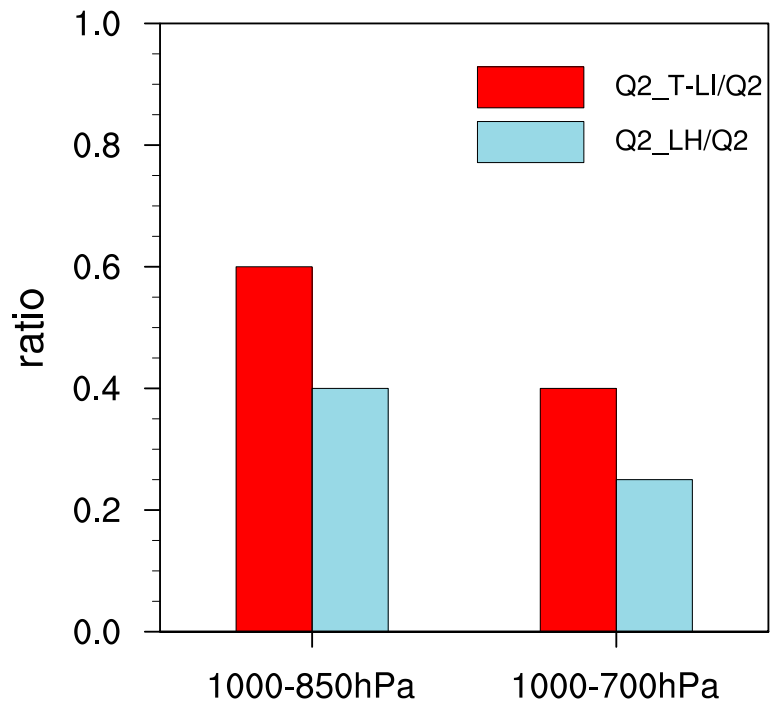

FIG. 10. The ratio of intraseasonal $Q_{2 \_ \text {T-LI }} / c_{p}$ and $Q_{2 \_ \text {LH }} / c_{p}$ contributing to intraseasonal $Q_{2} / c_{p}$ of the PBL (1000-700 and $1000-850 \mathrm{hPa}$ ) prior to the MJO convection peak (day -6 to day 0 ) to the east of the convection center $\left(15^{\circ}-5^{\circ} \mathrm{S}, 140^{\circ} \mathrm{E}-180^{\circ}\right)$. (Red bar is for $Q_{2 \_ \text {T-LI }} / c_{p}$ and blue bar is for $Q_{2 \_\mathrm{LH}} / c_{p}$.)

What are the specific processes through which HFW exert a strong nonlinear feedback to shallow clouds in front? By examining each term in $\overline{Q_{2} \mathrm{LH}}$ and $\overline{Q_{2 \_\mathrm{T}-\mathrm{LI}}}$, we found that the largest contribution arises from eddy meridional moisture advection $\left[-\overline{L v^{\prime}\left(\partial q^{\prime} / \partial y\right)}\right]$ (Fig. 11). In Northern Hemisphere winter, maximum mean moisture is located along $5^{\circ}-10^{\circ} \mathrm{S}$ over the $\mathrm{MC}$ and western Pacific. Advection of mean moisture by the northwesterly (southeasterly) of HFW would lead a positive (negative) specific humidity anomaly appearing in the southwest (southeast) of HFW circulation. During the MJO active phase when the MJO convection appears over $130^{\circ} \mathrm{E}$, the HFW wind anomaly weakens east of $150^{\circ} \mathrm{E}$ (Fig. 2). As a result, eddy meridional moisture advection weakens (Fig. 11a). During the MJO suppressed phase, the eddy moisture advection strengthens (Fig. 11b). The schematic diagrams of the HFW-MJO two-way interaction are shown in Fig. 12. In both the active and suppressed phases, the meridional eddy moisture advection is negative. Thus, relative to the climatology, this nonlinear term would lead to a positive $\widetilde{Q_{2}}$ anomaly during the MJO active phase, favorable for the development of shallow and congestus clouds, while an opposite process operates during the MJO suppressed phase. The positive $\widetilde{Q}_{2}$ anomaly to the east of MJO convection during the MJO active phase implies enhanced condensational heating in situ. This results from weakened HFW activity under an MJOinduced easterly vertical shear background condition. The weakened HFW activity during the MJO active 
MJO active phase

a. wind \& specific humidity

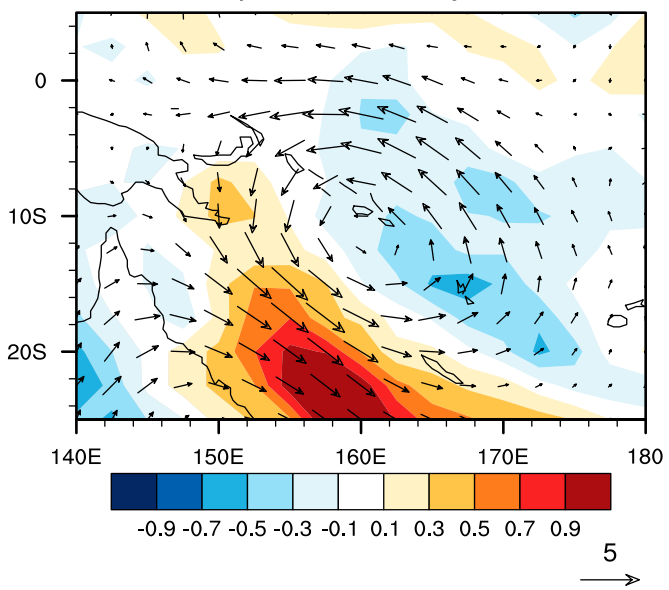

MJO suppressed phase

b. wind \& specific humidity

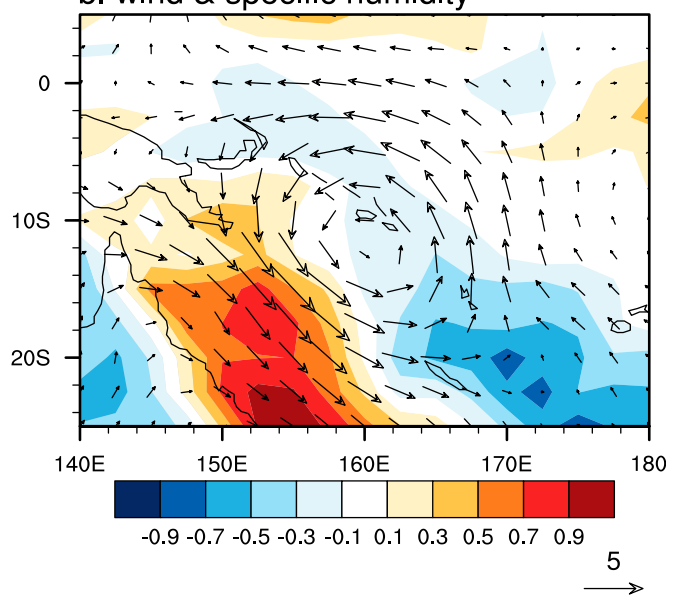

FIG. 11. (a) The 20-day high-pass filtered wind anomalies (unit: $\mathrm{m} \mathrm{s}^{-1}$ ) and specific humidity anomalies (unit: $\mathrm{g} \mathrm{kg}^{-1}$ ) at $850 \mathrm{hPa}$ during MJO active phase at day 0. (b) As in (a), but for the suppressed phase.

phase causes the weakened meridional eddy moisture transport and mixing, favoring the increase of MJOscale low-level moisture. The moisture increase destabilizes the lower troposphere and creates a favorable environment for development of congestus and deep convection to the east of MJO main convection.

\section{b. Upscale feedback due to eddy momentum transport}

In this section, we focus on the nonlinear rectification of MJO zonal momentum by HFW. Figure 13 shows the difference of intraseasonal zonal wind and zonal wind tendency between the MJO active and suppressed phases. We define the transitional region as a $20^{\circ}$ (longitude) $\times$ $10^{\circ}$ (latitude) region where the ISO zonal wind anomaly reverses sign (i.e., $\tilde{u}=0$ ); black dots in Fig. 13 indicate the center of longitude. A positive zonal wind tendency appears to the east of the maximum westerly center in the lower troposphere, while an opposite sign appears in the upper troposphere. Such a phase relation is consistent with MJO eastward propagation.

The zonal momentum equation on the intraseasonal time scale may be expressed as

$$
\begin{aligned}
\frac{\widetilde{\partial u}}{\partial t}= & \underbrace{\left(-\overline{\frac{\partial u^{\prime} u^{\prime}}{\partial x}}-\overline{\frac{\partial u^{\prime} v^{\prime}}{\partial y}}-\frac{\overline{\partial u^{\prime} \omega^{\prime}}}{\partial p}\right)}_{\text {termA } 1} \\
& +\overline{\left[-\overline{u^{\prime} \frac{\partial(\tilde{u}+\bar{u})}{\partial x}}-\overline{v^{\prime} \frac{\partial(\tilde{u}+\bar{u})}{\partial y}}-\overline{\left.\omega^{\prime} \frac{\partial(\tilde{u}+\bar{u})}{\partial p}\right]}\right.} \\
& +\underbrace{\left[-\overline{(\tilde{u}+\bar{u}) \frac{\partial u^{\prime}}{\partial x}}-\overline{(\tilde{v}+\bar{v}) \frac{\partial u^{\prime}}{\partial y}}-\overline{\left.(\tilde{\omega}+\bar{\omega}) \frac{\partial u^{\prime}}{\partial p}\right]}\right.}_{\text {termA } 2}
\end{aligned}
$$

$$
+\underbrace{\left[-\overline{(\tilde{u}+\bar{u}) \frac{\partial(\tilde{u}+\bar{u})}{\partial x}}-\overline{(\tilde{v}+\bar{v}) \frac{\partial(\tilde{u}+\bar{u})}{\partial y}}-\overline{(\tilde{\omega}+\bar{\omega}) \frac{\partial(\tilde{u}+\bar{u})}{\partial p}}-\frac{\widetilde{\partial \phi}}{\partial x}-f \tilde{v}\right]}_{\text {termB }},
$$

where $t$ denotes time, $u$ and $v$ are zonal and meridional wind, $p$ is the pressure, $\phi$ is geopotential height, and $f$ is the Coriolis parameter. Term A contains all terms involving the HFW while term B involves the mean and MJO flow components. Term A consists of the following three parts: 1) The eddy momentum flux divergence terms (term $A_{1}$ ), 2) advection of intraseasonal and LFBS momentum by
HFW flow (term $\mathrm{A}_{2}$ ), and 3) advection of HFW momentum by LFBS and intraseasonal winds (term $\mathrm{A}_{3}$ ). The sum of term A and term B is called term_Total. In the equation above, friction and turbulence flux terms are neglected, as we focus on our diagnosis at a constant $850-\mathrm{hPa}$ pressure level, while subgrid-scale turbulent flux (friction) terms are important only within the PBL. 

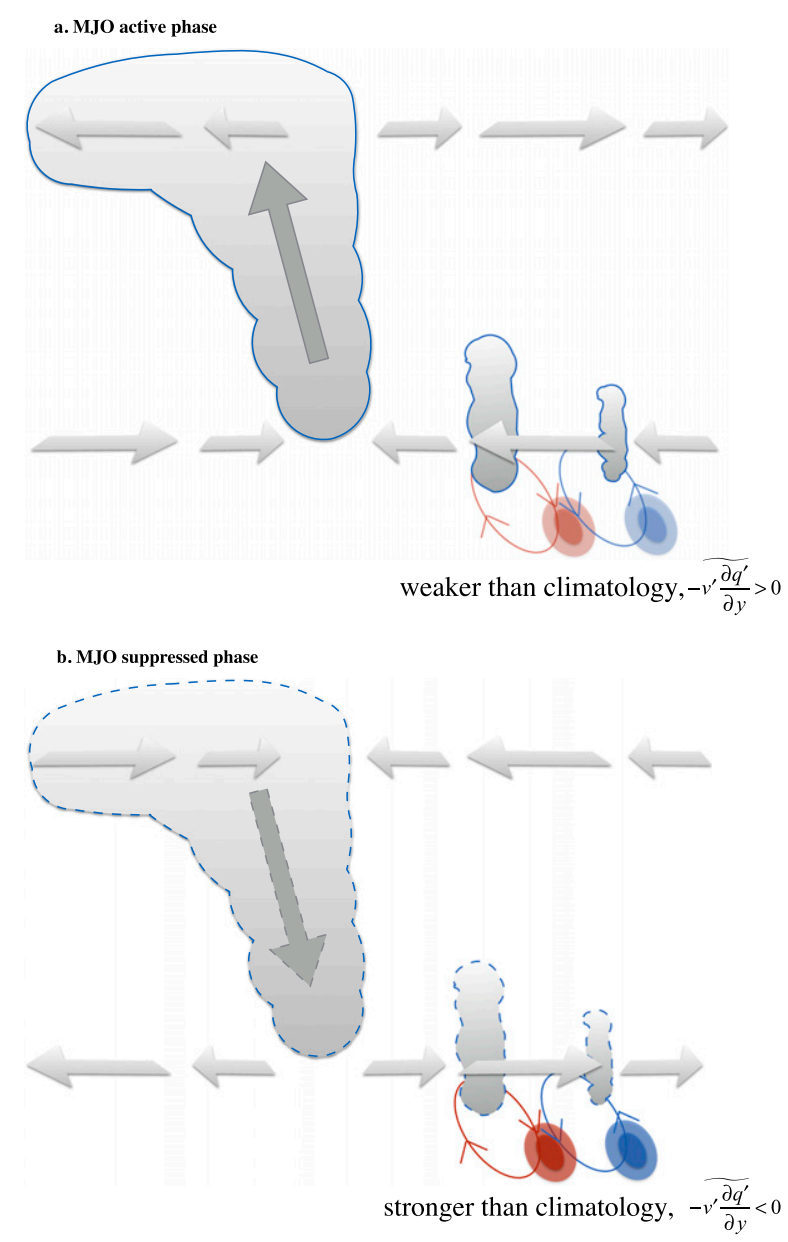

FIG. 12. (a) Schematic figure illustrating the mechanism of HFW meridional wind anomalies advecting HFW specific humidity anomalies contribution to $\widetilde{Q_{2}}$ in east of convection. (b) As in (a), but for the suppressed phase.

The percentage contribution of HFW-induced nonlinear rectification terms to the total MJO-scale zonal wind tendency in transitional region is shown in Fig. 14. In both the upper and lower troposphere the ratio of term $\mathrm{A} /$ term_Total is close to term $\mathrm{A} /(\partial u / \partial t)$, indicating that our momentum budget diagnosis is quite in balance. The maximum ratio (about $60 \%$ ) is at $850 \mathrm{hPa}$, indicating that a large portion of the intraseasonal zonal wind tendency at low levels is contributed by HFWinduced nonlinear rectification. Figure 15 shows the horizontal structure of $\overline{\partial u / \partial t}, \overline{\operatorname{term} \mathrm{A}}, \overline{\operatorname{term~B}}$, and $\widetilde{u^{\prime} u^{\prime}}$ at $850 \mathrm{hPa}$. The maximum term A center is close to the center of zonal wind tendency, $\overline{\partial u / \partial t}$. This indicates that through nonlinear rectification, the HFW contributes to the eastward propagation of MJO. The center of $\overline{\operatorname{term~B}}$, however, is in phase with the intraseasonal zonal wind center, indicating that $\overline{\text { term } B}$ tends to amplify MJO

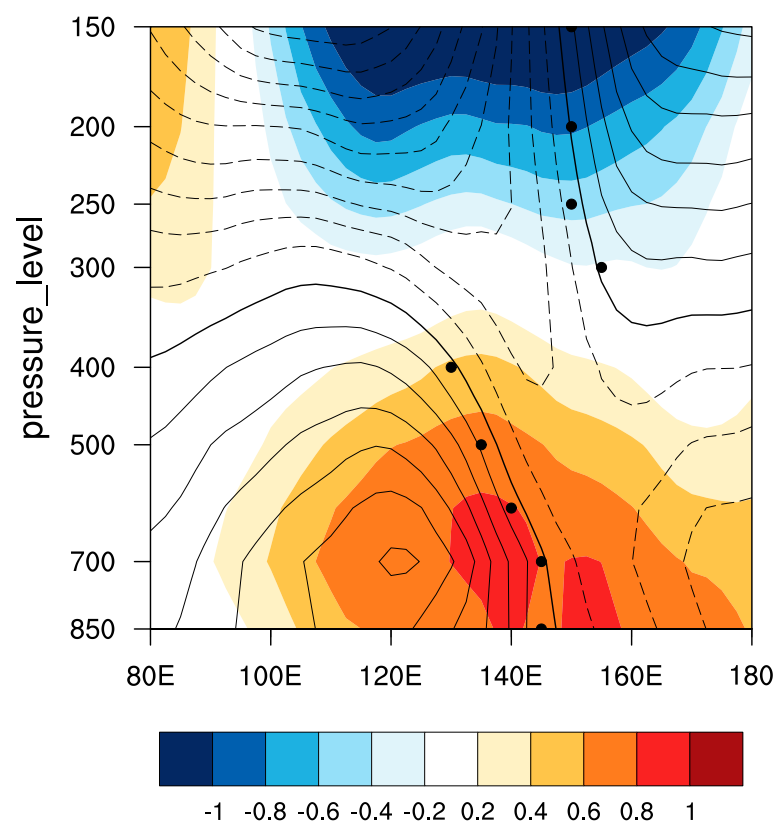

FIG. 13. Pressure-longitude cross section of intraseasonal filtered zonal wind anomaly (contour; unit: $\mathrm{m} \mathrm{s}^{-1}$; thick line is zero; interval is $1 \mathrm{~m} \mathrm{~s}^{-1}$ ) and zonal wind tendency anomaly (shading; unit: $10^{-5} \mathrm{~s}^{-1}$ ) averaged over $15^{\circ}-5^{\circ} \mathrm{S}$ for MJO active phase minus suppressed phase composite. (Black dots indicate the center of the transitional region of each pressure level.)

perturbation. In the following analyses, we intend to reveal physical mechanisms responsible for the upscale feedback. First, we examine the dominant term in term A. The budget of each term in term A is shown in Fig. 16. The greatest contribution arises from eddy zonal momentum flux divergence term [EZMFD, $-\overline{\left(\partial u^{\prime} u^{\prime} / \partial x\right)}$ ], which contributes to about $40 \%$ of HFW-induced nonlinearly rectified zonal wind tendency $(\overline{\operatorname{term} A})$. The current diagnosis indicates that eddy horizontal momentum flux divergence plays an important role in MJO zonal wind tendency. This seems contradictory to some previous works (e.g., Tung and Yanai 2002; Majda and Stechmann 2008; Majda and Stechmann 2009) that emphasized the role of eddy vertical momentum flux divergence. The difference may arise from the following aspects. First, the current diagnosis focuses on the transitional zone whereas the previous studies examined the role of eddy momentum transport over maximum MJO zonal wind variability region (Tung and Yanai 2002). As a result, the former is relevant to phase propagation while the latter is more related to instability. Second, some previous theoretical studies (e.g., Majda and Stechmann 2009; Khouider et al. 2012) prescribed the tilting of atmospheric waves or synoptic perturbations that are embedded within the MJO in 

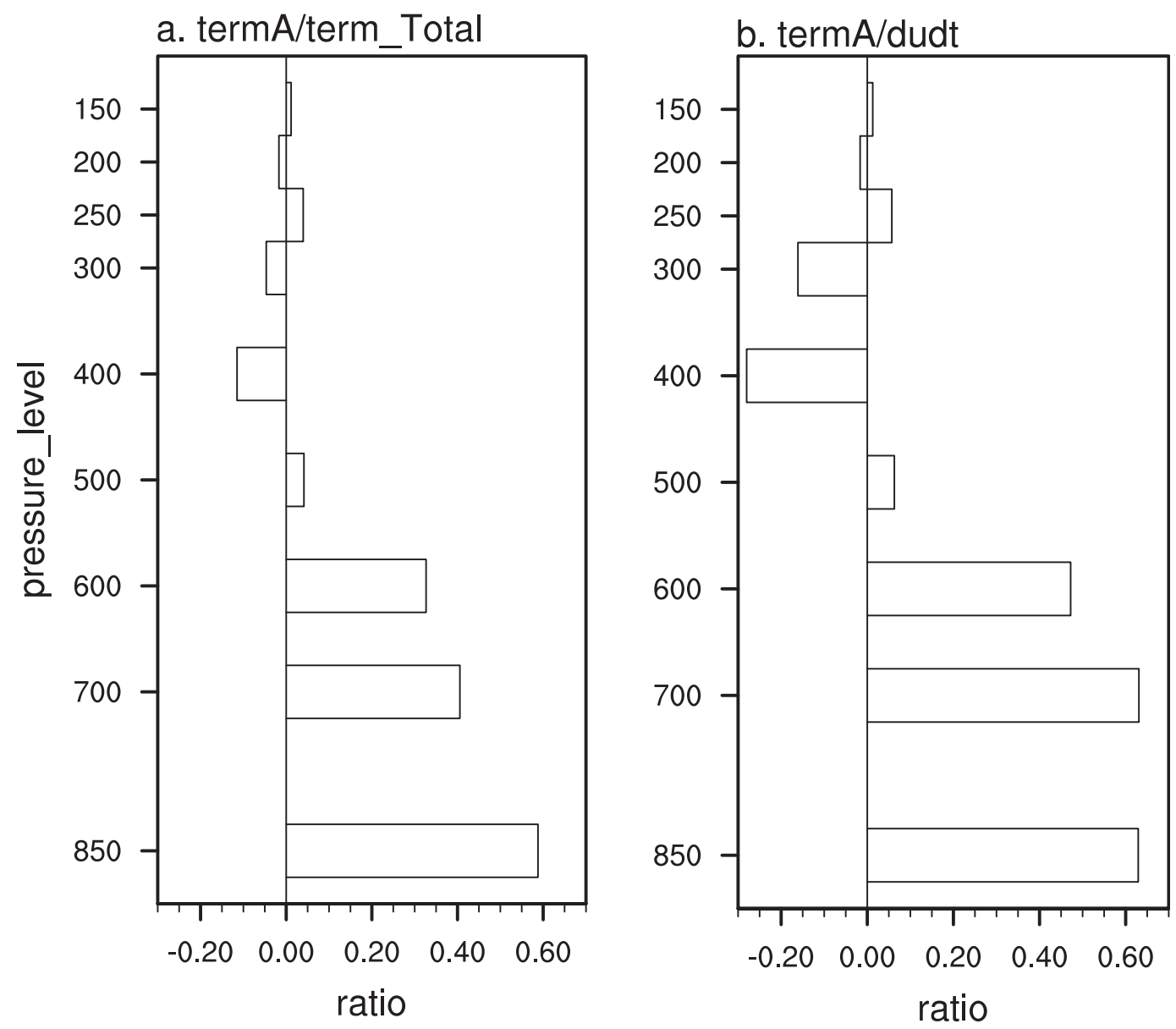

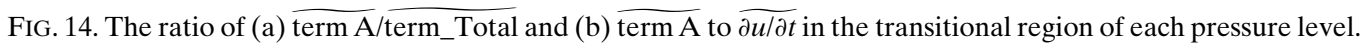

such a way that it favors MJO growth through eddy vertical momentum transport. But such a tilting structure and preferred location for distinctive low-frequency and high-frequency waves require further observational validation. While focusing on boreal summer ISO, Hsu and $\mathrm{Li}$ (2011) diagnosed the observational data in the western North Pacific and found that vertical eddy momentum transport is not as important as horizontal eddy momentum transport in a transitional region, which is consistent with the current study.

What is the mechanism behind the EZMFD contribution? Figure $15 \mathrm{~d}$ shows the intraseasonal zonal eddy momentum flux. One can see clearly a maximum center over the lower-level MJO westerly region during the MJO active phase and a minimum center over the MJO easterly region during suppressed phase. Thus, the divergence of the intraseasonal zonal eddy momentum flux in the transitional region is positive (negative) during the MJO active (suppressed) phase. This is consistent with the previous studies on convective momentum transport in the MJO (Tung and
Yanai 2002; Miyakawa et al. 2012). The positive (negative) intraseasonal zonal eddy momentum flux is caused by strengthened (weakened) HFW activity to the west (east) of MJO convection during its active phase. As discussed in section 3, HFW intensity is region-dependent (Fig. 2). The HFW activity is strengthened (weakened) under and to the west (to the east) of MJO convection during the MJO active phase. The enhanced HFW causes maximum (minimum) intraseasonal zonal eddy momentum flux over the MJO westerly (easterly) region. This leads to a positive zonal momentum flux divergence in the transitional region and promotes a positive zonal wind tendency. Figure 17 is a schematic diagram illustrating the twoway interaction mechanism between HFW and the MJO. The MJO modulates HFW intensity through induced vertical wind shear anomalies and specific humidity anomalies, while the modulated HFW activity exerts an upscale feedback to the MJO wind fields through the nonlinear rectification of eddy momentum transport. 


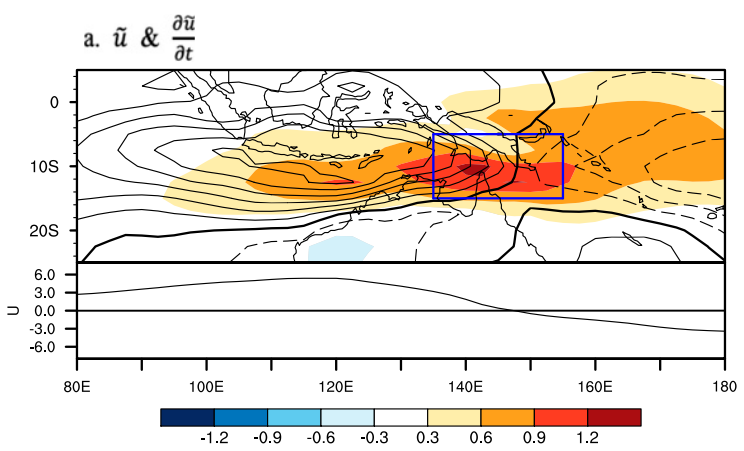

b. $\widetilde{\operatorname{term} A}$

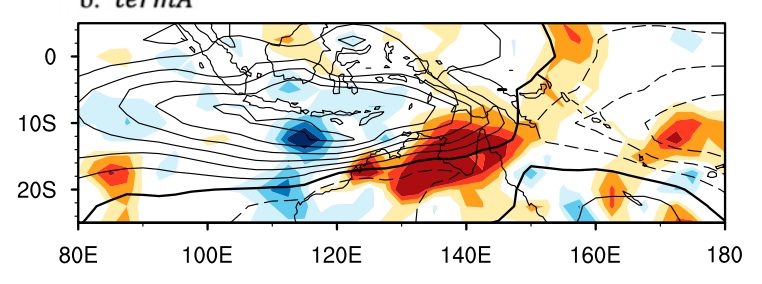

c. $t \widetilde{\operatorname{erm} B}$
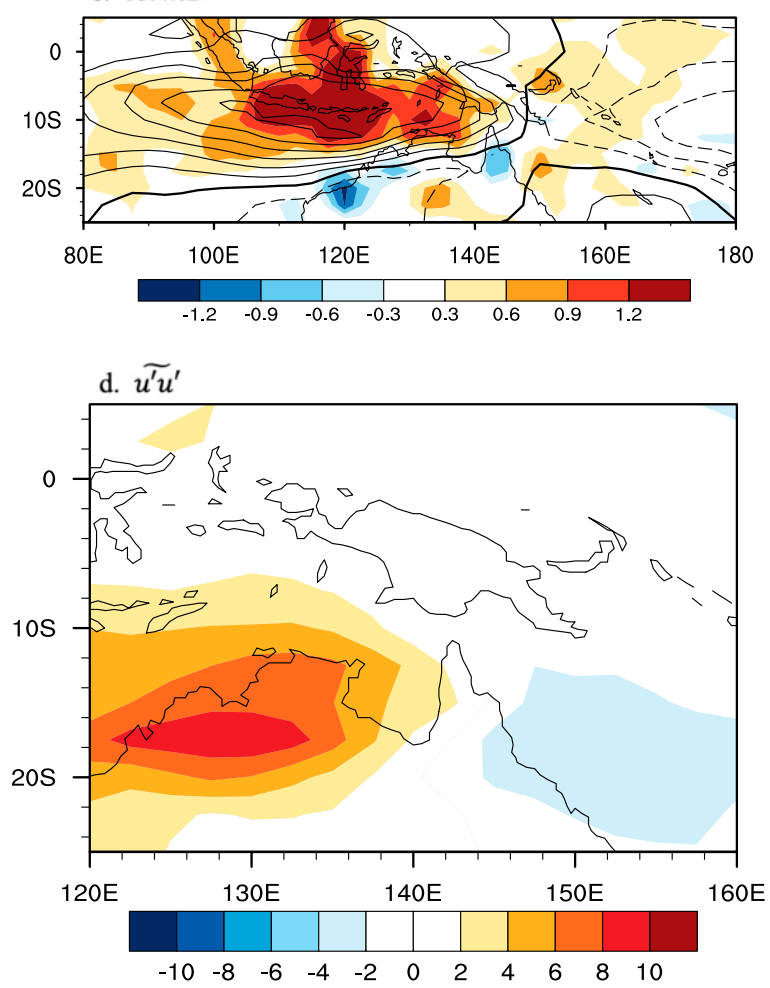

FIG. 15. (a) (top) The horizontal structure of $\tilde{u}$ (contour; unit: $\mathrm{m} \mathrm{s}^{-1}$; black thick line is zero and interval is $1 \mathrm{~m} \mathrm{~s}^{-1}$ ) and $\partial \tilde{u} / \partial t$ (shading; unit: $10^{-5} \mathrm{~s}^{-1}$ ) at $850 \mathrm{hPa}$ for MJO active phase minus suppressed phase composite. (bottom) The meridional averaged $\left(15^{\circ}-5^{\circ} \mathrm{S}\right)$ zonal wind (unit: $\mathrm{m} \mathrm{s}^{-1}$ ) for MJO active phase minus suppressed phase composite. The blue box in (a) is the transitional region for $850 \mathrm{hPa}$. (b),(c) As in (a, top), but shadings are for $\widehat{\operatorname{term} \mathrm{A}}$ and $\overline{\operatorname{term} \mathrm{B}}$, respectively. (d) The intraseasonal zonal eddy momentum flux $\left(\widehat{u^{\prime} u^{\prime}}\right)$ averaged from day -4 to day +2 (2-day interval) at $850 \mathrm{hPa}$ for the $\mathrm{MJO}$ active phase minus suppressed phase composite.

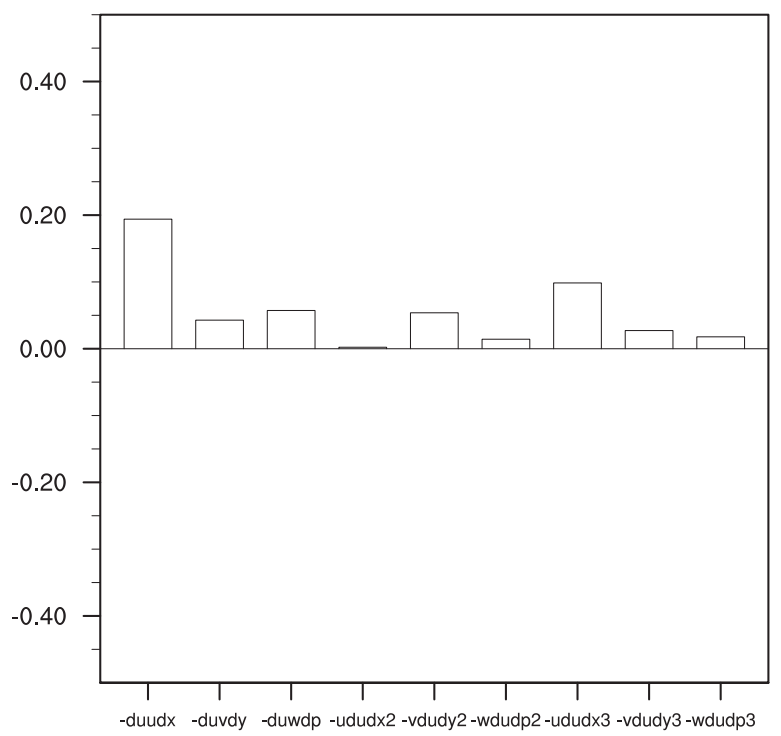

FIG. 16. The term $\mathrm{A}$ budget analysis at $850 \mathrm{hPa}$ averaged over transitional region for the MJO active phase minus suppressed phase composite $\left(15^{\circ}-5^{\circ} \mathrm{S}, 135^{\circ}-155^{\circ} \mathrm{E}\right)$ (unit: $\left.10^{-5} \mathrm{~s}^{-1}\right)$. The terms are $-\left(\overline{\partial u^{\prime} u^{\prime} / \partial x}\right)$, $\left.-\left(\overline{\partial u^{\prime} v^{\prime} / \partial y}\right), \quad-\left(\overline{\partial u^{\prime} w^{\prime} / \partial p}\right), \quad-\overline{u^{\prime}[\partial(\tilde{u}+\bar{u}) / \partial x}\right], \quad-\overline{v^{\prime}[\partial(\tilde{u}+\bar{u}) / \partial y}$, $-\overline{\omega^{\prime}[\partial(\tilde{u}+\bar{u}) / \partial p],}-\overline{(\tilde{u}+\bar{u})\left(\partial u^{\prime} / \partial x\right),}-\overline{-(\tilde{v}+\bar{v})\left(\partial u^{\prime} / \partial y\right)}, \quad$ and $-\overline{(\tilde{\omega}+\bar{\omega})\left(\partial u^{\prime} / \partial p\right)}$.

\section{Conclusions and discussion}

The interaction between the MJO and HFW in boreal winter was investigated with observational data and an intermediate tropical atmospheric model. We consider synoptic-scale vorticity disturbances as typical HFW. This work focuses on the MC region, a critical location for MJO eastward propagation and where climate models have difficulties in simulating MJO intensity and phase propagation.

By analyzing observational data, we examined to what extent the standard deviation of 20-day high-pass filtered vorticity field and the evolution of horizontal structure of 20-day high-pass filtered wind and vorticity fields are modulated by the MJO. It was found that HFW activity was stronger (weaker) during MJO active (suppressed) phase over MC. The modulation of HFW by the MJO can be partially explained through barotropic energy conversion. The positive (negative) intraseasonal eddy kinetic energy ( $\overline{\mathrm{EKE}}$ ) is contributed by positive (negative) intraseasonal barotropic energy conversion $(\widetilde{\mathrm{CK}})$ during the MJO active (suppressed) phase. The region-dependent HFW intensity variation is also likely to be modulated by MJO vertical wind shear anomaly and specific humidity anomaly. Easterly (westerly) wind shear anomaly and increased (decreased) background moisture favor (inhibit) the growth of HFW intensity to the west (east) of the MJO 


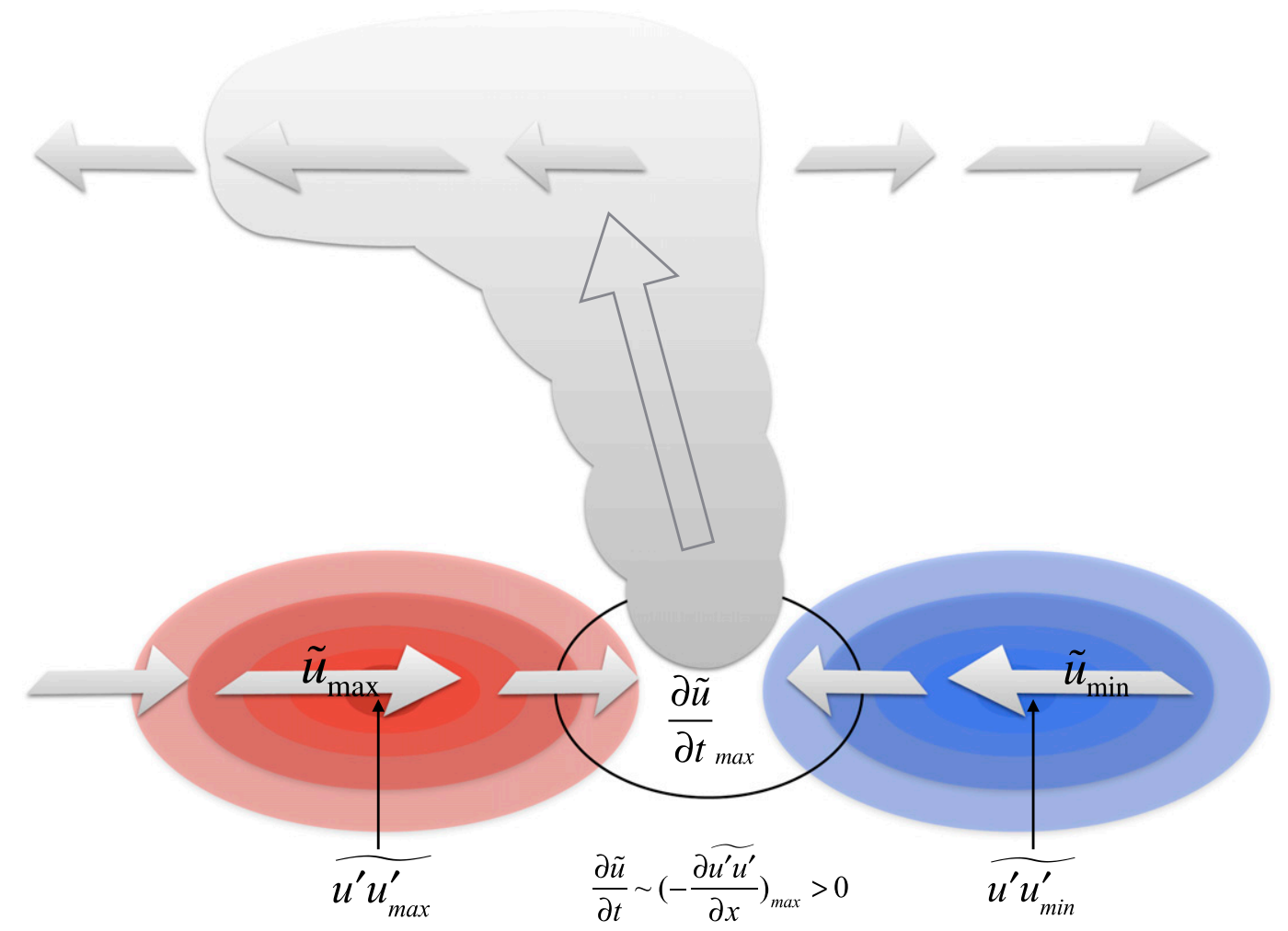

FIG. 17. Schematic figure illustrating the mechanism of upscale feedback of intraseasonal eddy momentum flux divergence $\left[-\left(\overline{\partial u^{\prime} u^{\prime} / \partial x}\right)\right]$ to MJO zonal wind tendency.

convective center. The results of model simulations confirm that the effects of the ISO moisture anomaly have primary impacts on HFW modulation, together with the effects of the vertical wind shear anomaly.

The upscale feedback of HFW to MJO is also investigated using the observational data. The enhanced (suppressed) HFW strongly feedbacks to MJO through nonlinear rectification of condensational heating and eddy momentum transport. We investigated the feedback to the ISO moisture anomalies and ISO wind fields (zonal wind shear) through nonlinear transport of moisture and momentum associated with HFW. The examination of feedback of intraseasonal apparent moisture sink $\left(\widetilde{Q_{2}}\right)$ shows that intraseasonal nonlinearly rectified $\widetilde{Q_{2}}\left(\widehat{Q_{2} \text { LH }}\right.$ and $\left.\widehat{Q_{2} \text { T-LI }}\right)$ contributes greatly to shallow and congestus heating in front of MJO deep convection. The contribution of the nonlinearly rectified heating (e.g., $\widehat{Q_{2 \_ \text {LH }}}$ or $\widehat{Q_{2 \_ \text {T-LI }}}$ ) to total $\widetilde{Q_{2}}$ can reach $25 \%-40 \%$ for the vertical layer of $1000-700 \mathrm{hPa}$ and $40 \%-60 \%$ for the layer of $1000-850 \mathrm{hPa}$. It implies that HFW-induced nonlinear rectification plays an important role in establishment of shallow and congestus convection in front, which supports MJO eastward propagation. The analysis of $\overline{Q_{2} \text { LH }}$ and $\widehat{Q_{2} \text { T-LI }}$ shows that they are dominated by eddy meridional moisture advection $\left[-L \overline{v^{\prime}\left(\partial q^{\prime} / \partial y\right)}\right]$. The negative eddy meridional moisture advection is weakened (strengthened) during MJO active (suppressed) phase. Thus, it leads to a positive $\widetilde{Q_{2}}$ anomaly during MJO active phase, which supports the development of shallow and congestus clouds in front of MJO convection. On the contrary, it results a negative $\widetilde{Q_{2}}$ anomaly during MJO suppressed phase.

For eddy momentum transport, different from modulation of intraseasonal eddy kinetic energy $(\widetilde{\mathrm{EKE}})$ by MJO time scale flow, it focuses on how eddies exert modulation on MJO momentum. It is found that a large portion of the intraseasonal zonal wind tendency is contributed by nonlinear rectification of HFW $\overline{(\operatorname{term~A})}$ and the largest contribution appears at $850 \mathrm{hPa}$ (about $60 \%$ ). The contribution of term A arises primarily from intraseasonal eddy zonal momentum flux divergence $\left[-\left(\overline{\partial u^{\prime} u^{\prime} / \partial x}\right)\right]$ (about $\left.40 \%\right)$. The physical explanation of the eddy zonal momentum flux contribution is as follows. The HFW zonal wind anomaly is strengthened (weakened) to the west (east) of MJO convection due to the impact of the easterly (westerly) wind shear anomaly and specific humidity anomaly. This causes a positive (negative) intraseasonal zonal eddy momentum flux anomaly to the west (east) and thus a positive $-\left(\overline{\partial u^{\prime} u^{\prime} / \partial x}\right)$ 
in the transitional region during $\mathrm{MJO}$ active phase, which favors $\mathrm{MJO}$ eastward propagation. A similar process operates during the MJO suppressed phase. Thus, this study provides a new comprehensive picture of the twoway interactions between the MJO and HFW. Forthcoming investigations will be extended to the interactions among locally forced diurnal variation (e.g., over land and ocean in the MC), HFW, and MJO.

The discovery of two-way interaction between $\mathrm{MJO}$ and HFW may shed some light on improving the MJO simulations over the Maritime Continent in climate models. It has been shown that multiscale variabilities, ranging from diurnal cycle and high-frequency tropical waves to MJO and interannual time scales, are very active over the Maritime Continent. Scale interactions among these motions may have a profound impact on MJO structure and evolution. Given the importance of multiscale interactions, more effort should be devoted into improving the simulations of these high-frequency perturbations and their interaction with $\mathrm{MJO}$ and other low-frequency modes in the climate models. It is anticipated that with improved multiscale interactions, climate models should be able to reproduce more realistic MJO structure and propagation behaviors over the Maritime Continent.

Acknowledgments. This work was supported by National Key R\&D Program 2018YFC1505804, NOAA Grant NA18OAR4310298, NSF AGS-1643297, NSFC Grants 41875069/41575043, and the JAMSTEC JIJI Theme 1 project. This is SOEST contribution number 10676 and IPRC contribution number 1373.

\section{REFERENCES}

Adames, Á. F., and J. M. Wallace, 2014: Three-dimensional structure and evolution of the vertical velocity and divergence fields in the MJO. J. Atmos. Sci., 71, 4661-4681, https://doi.org/ 10.1175/JAS-D-14-0091.1.

Benedict, J. J., and D. A. Randall, 2007: Observed characteristics of the MJO relative to maximum rainfall. J. Atmos. Sci., 64, 2332-2354, https://doi.org/10.1175/JAS3968.1.

Chang, C. P., P. A. Harr, and H.-J. Chen, 2005: Synoptic disturbances over the equatorial South China Sea and western Maritime Continent during boreal winter. Mon. Wea. Rev., 133, 489-503, https://doi.org/10.1175/MWR-2868.1.

Dee, D. P., and Coauthors, 2011: The ERA-Interim reanalysis: Configuration and performance of the data assimilation system. Quart. J. Roy. Meteor. Soc., 137, 553-597, https://doi.org/ 10.1002/qj.828.

Deng, L., and T. Li, 2016: Relative roles of background moisture and vertical shear in regulating interannual variability of boreal summer intraseasonal oscillations. J. Climate, 29, 70097025, https://doi.org/10.1175/JCLI-D-15-0498.1.

Dickinson, M., and J. Molinari, 2002: Mixed Rossby-gravity waves and western Pacific tropical cyclogenesis. Part I: Synoptic evolution. J. Atmos. Sci., 59, 2183-2196, https://doi.org/10.1175/15200469(2002)059<2183:MRGWAW >2.0.CO;2.
Duchon, C. E., 1979: Lanczos filtering in one and two dimensions. J. Appl. Meteor., 18, 1016-1022, https://doi.org/10.1175/15200450(1979)018<1016:LFIOAT > 2.0.CO;2.

Feng, J., T. Li, and W. Zhu, 2015: Propagating and nonpropagating MJO events over Maritime Continent. J. Climate, 28, 84308449, https://doi.org/10.1175/JCLI-D-15-0085.1.

Ge, X., T. Li, and X. Zhou, 2007: Tropical cyclone energy dispersion under vertical shears. Geophys. Res. Lett., 34, L23807, https://doi.org/10.1029/2007GL031867.

Hendon, H. H., and M. L. Salby, 1994: The life cycle of the MaddenJulian oscillation. J. Atmos. Sci., 51, 2225-2237, https://doi.org/ 10.1175/1520-0469(1994)051<2225:TLCOTM > 2.0.CO;2.

Hsu, P.-C., and T. Li, 2011: Interactions between boreal summer intraseasonal oscillations and synoptic-scale disturbances over the western North Pacific. Part II: Apparent heat and moisture sources and eddy momentum transport. J. Climate, 24, 942961, https://doi.org/10.1175/2010JCLI3834.1.

_ and - 2012: Role of the boundary layer moisture asymmetry in causing the eastward propagation of the MaddenJulian oscillation. J. Climate, 25, 4914-4931, https://doi.org/ 10.1175/JCLI-D-11-00310.1.

$\longrightarrow,-$, and C.-H. Tsou, 2011: Interactions between boreal summer intraseasonal oscillations and synoptic-scale disturbances over the western North Pacific. Part I: Energetics diagnosis. J. Climate, 24, 927-941, https://doi.org/10.1175/ 2010JCLI3833.1.

Jiang, X., and Coauthors, 2015: Vertical structure and physical processes of the Madden-Julian oscillation: Exploring key model physics in climate simulations. J. Geophys. Res., 120, 4718-4748, https://doi.org/10.1002/2014JD022375.

Kang, W., and E. Tziperman, 2018: The MJO-SSW teleconnection: Interaction between $\mathrm{MJO}$-forced waves and the midlatitude jet. Geophys. Res. Lett., 45, 4400-4409, https://doi.org/10.1029/ 2018 GL077937.

Kerns, B. W., and S. S. Chen, 2014: Equatorial dry air intrusion and related synoptic variability in MJO initiation during DYNAMO. Mon. Wea. Rev., 142, 1326-1343, https://doi.org/ 10.1175/MWR-D-13-00159.1.

Khouider, B., Y. Han, and J. A. Biello, 2012: Convective momentum transport in a simple multicloud model for organized convection. J. Atmos. Sci., 69, 281-302, https://doi.org/10.1175/ JAS-D-11-042.1.

Kim, D., and Coauthors, 2009: Application of MJO simulation diagnostics to climate models. J. Climate, 22, 6413-6436, https://doi.org/10.1175/2009JCLI3063.1.

_ propagating Madden-Julian oscillation events. J. Climate, 27, 111-125, https://doi.org/10.1175/JCLI-D-13-00084.1.

Knutson, T. R., and K. M. Weickmann, 1987: 30-60 day atmospheric oscillations: Composite life cycles of convection and circulation anomalies. Mon. Wea. Rev., 115, 1407-1436, https://doi.org/ 10.1175/1520-0493(1987)115<1407:DAOCLC>2.0.CO;2.

Lau, K.-H., and N.-C. Lau, 1990: Observed structure and propagation characteristics of tropical summertime synoptic scale disturbances. Mon. Wea. Rev., 118, 1888-1913, https://doi.org/ 10.1175/1520-0493(1990)118<1888:OSAPCO > 2.0.CO;2.

$\mathrm{Li}, \mathrm{T} ., 2006$ : Origin of the summertime synoptic-scale wave train in the western North Pacific. J. Atmos. Sci., 63, 1093-1102, https://doi.org/10.1175/JAS3676.1.

, and B. Wang, 1994: The influence of sea surface temperature on the tropical intraseasonal oscillation: A numerical study. Mon. Wea. Rev., 122, 2349-2362, https://doi.org/10.1175/15200493(1994)122<2349:TIOSST>2.0.CO;2. 
— , and C. Zhou, 2009: Planetary scale selection of the MaddenJulian oscillation. J. Atmos. Sci., 66, 2429-2443, https://doi.org/ 10.1175/2009JAS2968.1.

Liebmann, B., and C. A. Smith, 1996: Description of a complete (interpolated) outgoing longwave radiation dataset. Bull. Amer. Meteor. Soc., 77, 1275-1277.

Lin, J.-L., and Coauthors, 2006: Tropical intraseasonal variability in 14 IPCC AR4 climate models. Part I: Convective signals. J. Climate, 19, 2665-2690, https://doi.org/10.1175/JCLI3735.1.

Liu, F., and B. Wang, 2013: Impacts of upscale heat and momentum transfer by moist Kelvin waves on the Madden-Julian oscillation: A theoretical model study. Climate Dyn., 40, 213-224, https://doi.org/10.1007/s00382-011-1281-0.

Madden, R. A., and P. R. Julian, 1972: Description of global-scale circulation cells in the tropics with a 40-50 day period. J. Atmos. Sci., 29, 1109-1123, https://doi.org/10.1175/15200469(1972)029<1109:DOGSCC > 2.0.CO;2.

Majda, A. J., and S. N. Stechmann, 2008: Stochastic models for convective momentum transport. Proc. Natl. Acad. Sci. USA, 105, 17 614-17 619, https://doi.org/10.1073/pnas.0806838105.

—_, and _ 2009: A simple dynamical model with features of convective momentum transport. J. Atmos. Sci., 66, 373-392, https://doi.org/10.1175/2008JAS2805.1.

Maloney, E. D., 2009: The moist static energy budget of a composite tropical intraseasonal oscillation in a climate model. J. Climate, 22, 711-729, https://doi.org/10.1175/2008JCLI2542.1.

Matsuno, T., 1966: Quasi-geostrophic motions in the equatorial area. J. Meteor. Soc. Japan, 44, 25-43, https://doi.org/10.2151/ jmsj1965.44.1_25.

Matthews, A. J., 2008: Primary and successive events in the Madden-Julian oscillation. Quart. J. Roy. Meteor. Soc., 134, 439-453, https://doi.org/10.1002/qj.224.

Miyakawa, T., Y. N. Takayabu, T. Nasuno, H. Miura, M. Satoh, and M. Moncrieff, 2012: Convective momentum transport by rainbands within a Madden-Julian Oscillation in a global nonhydrostatic model with explicit deep convective processes. Part I: Methodology and general results. J. Atmos. Sci., 69, 1317-1338, https://doi.org/10.1175/JAS-D-11-024.1.

Nasuno, T., T. Li, and K. Kikuchi, 2015: Moistening processes before the convective initiation of Madden-Julian oscillation events during the CINDY2011/DYNAMO period. Mon. Wea. Rev., 143, 622-643, https://doi.org/10.1175/MWR-D-14-00132.1.

_- K. Kikuchi, M. Nakano, Y. Yamada, M. Ikeda, and H. Taniguchi, 2017: Evaluation of the near real-time forecasts using a global nonhydrostatic model during the CINDY2011/ DYNAMO. J. Meteor. Soc. Japan, 95, 345-368, https://doi.org/ 10.2151/jmsj.2017-022.

Neelin, J. D., I. M. Held, and K. H. Cook, 1987: Evaporation-wind feedback and low-frequency variability in the tropical atmosphere. J. Atmos. Sci., 44, 2341-2348, https://doi.org/10.1175/ 1520-0469(1987)044<2341:EWFALF>2.0.CO;2.

Rui, H., and B. Wang, 1990: Development characteristics and dynamic structure of tropical intraseasonal convection anomalies. J. Atmos. Sci., 47, 357-379, https://doi.org/10.1175/ 1520-0469(1990)047<0357:DCADSO > 2.0.CO;2.

Sperber, K. R., 2003: Propagation and the vertical structure of the Madden-Julian oscillation. Mon. Wea. Rev., 131,
3018-3037, https://doi.org/10.1175/1520-0493(2003)131<3018: PATVSO $>2.0 . \mathrm{CO} ; 2$.

Straub, K. H., 2013: MJO initiation in the real-time multivariate MJO index. J. Climate, 26, 1130-1151, https://doi.org/10.1175/ JCLI-D-12-00074.1.

- , and G. N. Kiladis, 2003: Interactions between the boreal summer intraseasonal oscillation and higher-frequency tropical wave activity. Mon. Wea. Rev., 131, 945-960, https://doi.org/10.1175/ 1520-0493(2003)131<0945:IBTBSI > 2.0.CO;2.

Tung, W.-W., and M. Yanai, 2002: Convective momentum transport observed during the TOGA COARE IOP. Part I: General features. J. Atmos. Sci., 59, 1857-1871, https://doi.org/ 10.1175/1520-0469(2002)059<1857:CMTODT>2.0.CO;2.

Wang, B., 1988: Dynamics of tropical low-frequency waves: An analysis of the moist Kelvin wave. J. Atmos. Sci., 45, 2051-2065, https:// doi.org/10.1175/1520-0469(1988)045<2051:DOTLFW>2.0.CO;2. , and H. Rui, 1990: Dynamics of the coupled moist KelvinRossby wave on an equatorial $\beta$-plane. J. Atmos. Sci., 47, 397-413, https://doi.org/10.1175/1520-0469(1990)047<0397: DOTCMK $>2.0 . \mathrm{CO} ; 2$.

, and T. Li, 1993: A simple tropical atmosphere model of relevance to short-term climate variations. J. Atmos. Sci., 50, 260-284, https://doi.org/10.1175/1520-0469(1993)050<0260: ASTAMO $>2.0 . \mathrm{CO} ; 2$.

, and - 1994: Convective interaction with boundary-layer dynamics in the development of a tropical intraseasonal system. J. Atmos. Sci., 51, 1386-1400, https://doi.org/10.1175/ 1520-0469(1994)051<1386:CIWBLD>2.0.CO;2.

— cally sheared zonal flow. Part I: Stable waves. J. Atmos. Sci., 53, 449-467, https://doi.org/10.1175/1520-0469(1996)053<0449: LFEWIV $>2.0 . \mathrm{CO} ; 2$.

_, and — 1997: A model for the boreal summer intraseasonal oscillation. J. Atmos. Sci., 54, 72-86, https://doi.org/10.1175/ 1520-0469(1997)054<0072:AMFTBS >2.0.CO;2.

Wang, L., and L. Chen, 2017: Effect of basic state on seasonal variation of convectively coupled Rossby wave. Dyn. Atmos. Oceans, 77, 54-63, https://doi.org/10.1016/j.dynatmoce.2016.11.002.

Yanai, M., S. Esbensen, and J.-H. Chu, 1973: Determination of bulk properties of tropical cloud clusters from large-scale heat and moisture budgets. J. Atmos. Sci., 30, 611-627, https://doi.org/ 10.1175/1520-0469(1973)030<0611:DOBPOT $>2.0 . C O ; 2$

Zhao, C., T. Li, and T. Zhou, 2013: Precursor signals and processes associated with MJO initiation over the tropical Indian Ocean. J. Climate, 26, 291-307, https://doi.org/10.1175/JCLI-D-12-00113.1.

Zhou, C., and T. Li, 2010: Upscale feedback of tropical synoptic variability to intraseasonal oscillations through the nonlinear rectification of the surface latent heat flux. J. Climate, 23, 5738-5754, https://doi.org/10.1175/2010JCLI3468.1.

Zhu, H., and H. H. Hendon, 2015: Role of large-scale moisture advection for simulation of the MJO with increased entrainment. Quart. J. Roy. Meteor. Soc., 141, 2127-2136, https:// doi.org/10.1002/qj.2510.

, - — and C. Jakob, 2009: Convection in a parameterized and superparameterized model and its role in the representation of the MJO. J. Atmos. Sci., 66, 2796-2811, https://doi.org/10.1175/ 2009JAS3097.1. 